\title{
Subjective Return Expectations, Information and Stock Market Participation: Evidence from France*
}

\author{
Luc Arrondel \\ Paris School of Economics-Banque de France \\ Derya Tas \\ University of Southampton \\ January 17, 2012
}

\begin{abstract}
Despite of its importance for the economy, stock ownership by households is poorly understood. Recent research has uncovered that expectations of stock market returns by individuals strongly correlate with stock ownership. This paper reports new findings from a survey that collected data on stock-market return expectations, individual information sets and stock ownership, for a representative sample by age and wealth ('Mode de vie des Français', TNS 2007). Individual information sets measure in probabilistic terms the beliefs that individuals hold about equity returns over the last five years. We find that (i) expected returns and information sets are very heterogeneous, hump-shaped in age, higher for males and increasing in wealth; (ii) stock ownership increases with the subjective conditional expectation of a positive return; and (iii) that information is costly acquired, sourced from social interactions, professionals, specialised media access, or own past experience, and is consistent with rational inattentiveness amongst optimists and income constrained respondents.
\end{abstract}

Keywords: Subjective Expectations, Information, Stock Market Participation, Household Finance

JEL Codes: D12, D8, G11

\footnotetext{
${ }^{*}$ The authors thank Toke Aidt, Adeline Delavande, Antonio Cabrales, Chuck Manski, Andre Masson, Alessandro Mennuni, Xisco Oliver and Jian Tong for their various comments, and seminar audiences at the 2nd. Dauphine Workshop on Economic Theory "Recent Advances on the Role of Beliefs in Decision Theory", Nottingham University, PSE (Economie et Psychologie), the RES 2011 annual meeting, and at the University of Cambridge. The first author gratefully acknowledges financial support from the "Agence Nationale pour la Recherche" (ANR), and the second from the ESRC (RES-061-25-0327). The second author would also like to thank Toke Aidt for his hospitality at the Unviersity of Cambridge, where this piece was written.
} 


\section{Introduction}

Prior to the 2008 financial crisis, nonparticipation in risky asset markets was awarded the status of 'financial mistake', with potentially large consequences for equilibrium asset prices and the equity premium. ${ }^{1}$ The 'nonparticipation' puzzle uncovers the fact that a significant fraction of households hold no risky assets despite of their historical excess average returns over riskless assets, or 'equity premium' (Haliassos and Bertaut, 1995). To date, and since the educated and the wealthier are more likely to participate, transactions and information costs remain the most important quantitatively (Vissing-Jorgensen, 2002; Haliassos and Michaelides, 2003). But several questions remain, like the nonparticipation of the wealthiest, or the precise nature of information costs. Recently uncovered factors such as trust (Guiso et al., 2008), financial literacy (Lusardi, 2008), 'financial awareness' (Guiso and Jappelli, 2005) or (time spent in acquiring) financial information (Guiso and Jappelli, 2006) are shaping our understanding of the nature and importance of financial information costs. Here, rather than embracing non-standard behaviour, we attempt to directly measure individual-level information sets and examine empirically the extent to which they matter in explaining nonparticipation.

But the crisis, that has so far lead to the "Great Recession", is also shaking the foundations of macro-economics (Hall, 2010). At the heart of the debate, is the role of expectations in state-ofthe-art macro-economic models, and in particular, in their financial counterparts (Stiglitz, 2011). The standard practice has been to adopt the rational expectations paradigm, whereby households hold a (common) statistically correct unbiased view of the future. Rational expectations have a crucial advantage: rather than attempting the difficult task of measuring expectations, they can be inferred from (past equilibrium) realizations. Because the stock market is a public nonmanipulable event, under rational expectations differences in household financial choices cannot be explained by differences in what they expect, only by differences in either what they want (preferences) or, in what they have (endowments) when participation is costly. Against this received wisdom, the importance of (heterogeneous) subjective expectations in financial markets has been ascertained from evidence gathered (i) in laboratory experiments (Hommes, 2011), (ii) from agentbased computational algorithms (Arthur, 2006), or (iii) from survey data (Pesaran and Weale, 2006), among others. We report evidence from survey data on households' stock market return expectations collected right before the financial crisis.

An incipient strand of new research in survey expectations reviewed in Hurd (2009), uncovers that households' expectations regarding the future evolution of the stock market are: (i) for the majority, no better than a 50-50 chance that the stock market index will go up in the year ahead, albeit (ii) extremely heterogeneous (Dominitz and Manski, 2007 and 2011); (iii) able to explain

\footnotetext{
${ }^{1}$ The more so, the larger the fraction of the wealthiest risk-tolerant households that does not participate, since the aggregate demand for risky assets disproportionately depends on them. And even amongst the wealthiest, nonparticipation remains strikingly high. See Campbell (2006) and the references therein.
} 
differences in financial choices both at a point in time, and through the life-cycle (Dominitz and Manski, 2007; Hurd, van Rooij and Winter, 2011; Miniaci and Pastorello, 2010), and (iv) able to identify households' implicit risk preferences, when combined with data on financial choices (Kézdi and Willis, 2009). These novel contributions rest on the methodological corner stone put by Dominitz and Manski (1997) and on Manski's (2004) influential article, who advocate for treating expectations as primitives of the model, and undertake probabilistic elicitation to obtain quantitative measures of individual expectations in surveys. So far, survey data has been exploited for (i) stock market investors only (Vissing-Jorgensen, 2004), for (ii) a specific population subgroup which includes non-stockholders (by age, Dominitz and Manski, 2007, 2011; Kézdi and Willis, 2009) and for (iii) a representative sample of the population by age and wealth (Hurd et al., 2011; Miniaci and Pastorello, 2010). Here, we exploit data from a new wave of the Taylor-Nelson Sofres French survey (TNS 2007), which contains information on attitudes, preferences, subjective expectations, individual information sets and socio-economic and demographic characteristics for a representative sample of 3,826 households, by age and wealth.

We contribute to this literature in three main directions: (i) methodologically, since we elicit probability densities instead of probability distributions and over a longer forecasting horizon (Pesaran and Weale, 2006), (ii) quantitatively, since we exploit survey data from a representative sample by both age and wealth (Campbell, 2006), and (iii) for the first time, we elicit probabilistically households' information sets. The latter is crucial, because "...little is known about what kind of information rational-expectations investors should learn. Since information learned determines which assets are invested in [...]" (Van Nieuwerburgh and Veldkamp, 2010). We find (i) less 50-50 percent responses to probability questions, possibly conveying absolute uncertainty, at the expense of (ii) more answers conveying absolute certainty, i.e. 0 ('no chance') and 100 ('for sure') type of answers; (iii) average five-year ahead probabilistic stock market forecasts appear hump-shaped in age, are higher for males and increase with total wealth, and (iv) increase with the probability of holding stocks but not with educational attainment. (v) Our measure of information, when averaged across individuals, is also hump-shaped in age (King and Leape, 1987), is higher for males, and increases with total wealth. Finally, (vi) the conditional cross-sectional average of five-year ahead probabilistic stock market forecasts also appears hump-shaped in age.

We adopt Dominitz and Manski's (2007) methodology, and find that conditioning on risk preferences, endowments, constraints, inertial/delegation factors and information, subjective expectations determine stock market participation (i) amongst the elderly, confirming the robustness of Dominitz and Manski's (2007) findings, and (ii) for all ages, but (iii) not amongst the young, for whom information appears instead crucial (King and Leape, 1987; Hurd, 2009). Our measure of information is consistent with information being costly acquired (Peress, 2004; Van Nieuwerburgh and Veldkamp, 2010), gathered from social interactions (Hong et al., 2004) and specialised media (Cabrales and Gottardi, 2011), and increases with own's past experience ('frequence of recent trades'). Optimists and income constrained respondents appear worse informed, consistent with rational inattention (Sims, 2003). However, it does not increase with the respondents' own or 
parents' educational attainment, family background, total wealth or respondents' preferences for either risk or time. Finally, (iv) the subjective expectations of the uninformed determine even more strongly stockownership. Hence, conditioning on what households know, subjective expectations determine actual choices, in line with elementary portfolio choice theory predictions (Arrow, 1965; Merton, 1969; Samuelson, 1969). ${ }^{2}$

The rest of the paper is organized as follows: in section 2 we describe the methodology used to elicit expectations and individual information sets, and construct measures of expectations similar to Dominitz and Manski (2007) to assess the quality of our data against the 2004 wave of the Health and Retirement Study (HRS 2004), which contains a much larger sample of households. In section 3 we describe the TNS 2007 data set and provide descriptive statistics. Section 4 reports the main empirical results on stock market participation, and section 5 concludes.

\section{Measuring Expectations and Information}

\subsection{Survey Design}

In surveys, respondents are asked to state their perception of a future event in order to understand if it determines their current behaviour. The recent literature on measuring expectations privileges the use of probability questions rather than eliciting point expectations or the traditional qualitative approach of attitudinal research (Manski, 2004). Answers to such questions are used to understand if expectations and outcomes are related, and to evaluate if individual behaviour changes in response to changes in expectations. Dominitz and Manski (2007) elicit individuals' expectations of stock market returns inquiring about how 'well' the respondent thinks the economy will do in the year ahead (Positive Nominal Return, PNR). They exploit data for a representative sample of the elderly from the 2004 wave of the U.S. Health and Retirement Study (HRS).

To validate our dataset, we build upon their work using a similar methodology, and extend it along different dimensions. First, by extending the forecasting horizon to five years, we intend to untie expectational answers from the bussiness-cycle conditions prevailing at the time of the survey (March 2007) to better capture (i) the historic average upward trend of the stock market index, and (ii) inertia in portfolio management (Bilias et al., 2010). The latter is important since it remains an open question with which horizon households invest in the stock market. Second, following the methodology of the Survey on Household Income and Wealth (SHIW) conducted by the Bank of Italy (Guiso et al., 1996), probability densities are elicited on seven points of the outcome space, instead of just two points of the cumulative distribution functions (cdfs.), to obtain more precise individual estimates of the relevant moments. Third, we exploit data from a representative sample by age, to examine the relationship between age-portfolio profiles and subjective expectations at the extensive margin. Finally and most importantly, probabilistic elicitation of recent past stock market performance (past Positive Nominal Return, pPNR) provides a quantitative measure of households'

\footnotetext{
${ }^{2}$ Here we abstract from non-expected utility models (e.g. Dow and Werlang, 1992), and focus only on the consistency of household choices whithin an expected utility framework.
} 
degree of awareness regarding their investment opportunity set, to capture: (i) differences in information across households, and (ii) the relationship between information and expectations (Van Nieuwerburgh and Veldkamp, 2010). Without it, households who do not invest because they expect the stock market to burst over the given forecasting horizon are indistinguishable from those who do not invest because they are unaware of the investment opportunities available in the stock market.

The new wave of the Taylor-Nelson Sofres French survey (TNS 2007) was designed by researchers at the Paris School of Economics (PSE), and administered by Taylor-Nelson Sofres, a professional agency paid with research funds from the Agence Nationale pour la Recherche (ANR). The first wave, carried in 2002, had no questions related to stock market expectations. The 2007 wave contains very detailed information on attitudes, preferences and expectations, in addition to wealth, income and socio-economic and demographic characteristics for a representative sample of French households. A questionnaire was sent to a representative sample of 4,000 individuals, corresponding to an equivalent number of households. Respondents had to fill the questionnaire, and return it by the post in exchange of around $€ 25$ in coupon-tickets (bons-d'achat). ${ }^{3} 3,826$ respondents sent their questionnaires back, representing a $97 \%$ response rate.

The survey was conducted in March 2007. Figure 1 below shows that after a drop of nearly $60 \%$ in the French stock market Index (CAC-40) caused by the 'dot-com crash' of 2001, by the time the survey was conducted, the stock market index had been steadily recovering since the mid 2002 . In March 2007 the index was still below its 'dot-com' peak. Hence, it is likely that respondents are particularly aware of the stock market evolution regarding the past, and provide very heterogeneous and uncertain answers regarding the stock market prospects for the five years to come, given the recent experience of a bust and a boom.

The density of nominal yearly (and 5-year rolling) log returns on the CAC-40 computed from monthly data between July 1987 and July 2011 is depicted in Figure 2, panel (a) (panel (b)). The distribution has moments $\mu=0.023(\mu(5)=0.108)$ and $\sigma=0.10(\sigma(5)=0.19)$. The densities depicted in Figure 2 can be thought as representing the subjective beliefs of those respondents who base them on the history of observed stock market index monthly closing values (and that are more likely to form a rational expectation $\left.{ }^{4}\right)$ :

\subsection{Expectations}

To measure expectations, we elicited households' subjective beliefs regarding the likely evolution of the stock market index five years ahead in time, $I_{t+5}$, relative to March 2007, $I_{t}$, from the following

\footnotetext{
${ }^{3}$ Within it, the survey contains a small sample of 798 households has a panel dimension, linking to the previous TNS-2002 survey (4,000 35-55 year-old households) and of 2,234 households linking to the new TNS-2009 (4,000 households). As well, a complementary experimental module which could voluntarily be filled on-line (400 individuals corresponding to 400 households) in exchange of a variable remuneration $(€ 5,000$ shared in prizes in the form of lotteries) was introduced. Neither is exploited here.

${ }^{4}$ In line with the literature on adaptive learning, summarized in Evans and Honkapohja (2001), where even if individuals are uncertain about the underlying structure of the economy, they may end up learning it in the limit from equilibrium realizations, under very general conditions.
} 


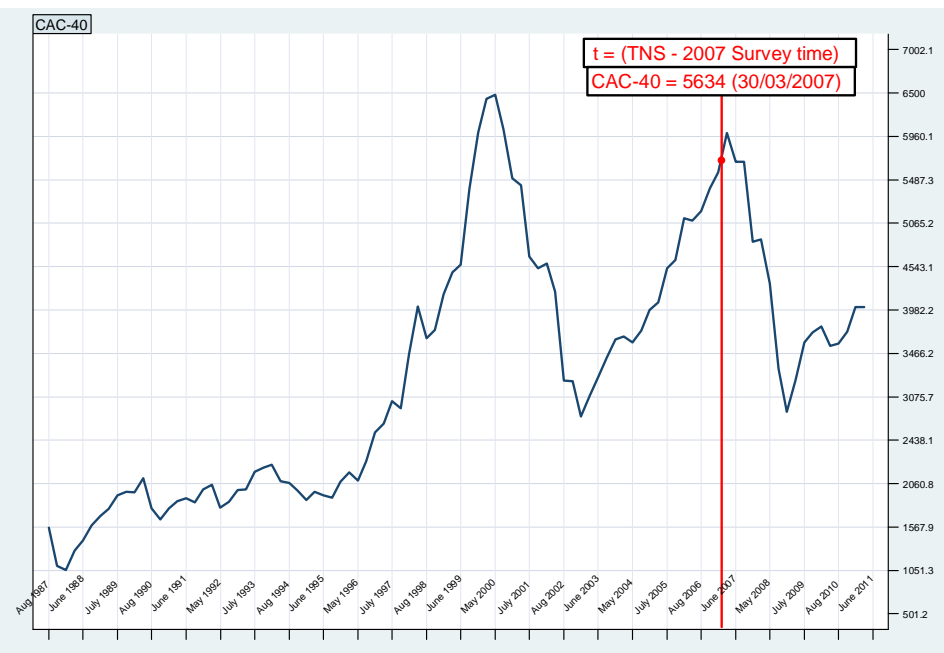

Figure 1: French Stock Market Index CAC-40 between July 1987 and July 2011. The survey was conducted in March 2007. Source: Author's own calculations from MSN Money hsitorical data.

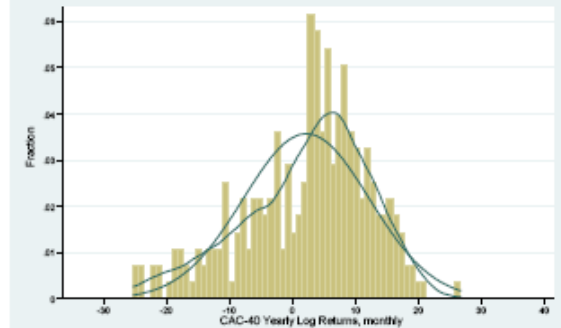

Panel (a): 1-year log-returns.

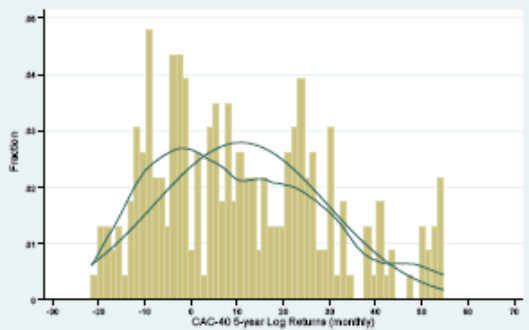

Panel (b): 5-year log-returns.

Figure 2: Histogram of CAC-40 index log-returns, computed at 1-year (panel a) and 5-year (panel b) rolling window frequencies. Source: Author's own calculations using monthly data between July 1987 and July 2011, available online from MSN Money. 
questions (translated wording):

C6. 'Five years from now, do you think that the stock market... -For each category write down the likelihood of occurrence assigning a value between 0 and 100. The sum of all your answers must be equal to 100-:

... will have increased by more than $25 \%$

... will have increased by 10 to $25 \%$

... will have increased by less than $10 \%$

... will be the same

... will have decreased by less than $10 \%$

... will have decreased by 10 to $25 \%$

... will have decreased by more than $25 \%$

C7b. 'In your opinion, if you expect the stock market to increase within the next 5 years, which would be the highest possible increase (as a percentage)?'

C8b. 'In your opinion, if you expect the stock market to decrease within the next 5 years, which would be the lowest possible decrease (as a percentage)?'

Question C6 inquires household $i$ about the subjective relative likelihood of occurrence, $p_{t+1, k}^{i}$, of each of the seven alternative scenarios, $k=1, \ldots, 7$. Each scenario represents a possible outcome range for the percentage change in the index between $t$ and $t+5, R_{t+1}(5) \equiv \frac{I_{t+5}}{I_{t}}-1 .^{5}$ Questions $\mathrm{C} 7 \mathrm{~b}$ and $\mathrm{C} 8 \mathrm{~b}$ provide subjective upper and lower bounds for the percentage change, $R_{\max }^{i}$ and $R_{\min }^{i}$ respectively. The corresponding outcome ranges are:

$$
R_{t+1} \in\{\underbrace{\left[R_{\max }^{i}, 0.25\right)}_{k=1}, \underbrace{[0.25,0.10]}_{k=2}, \underbrace{(0.10,0)}_{k=3}, \underbrace{\{0\}}_{k=4}, \underbrace{(0,-0.10)}_{k=5}, \underbrace{[-0.10,-0.25]}_{k=6}, \underbrace{\left(-0.25,-R_{\min }^{i}\right]}_{k=7},\}
$$

and households' subjective likelihoods are accordingly:

$$
p_{t+1, k}^{i} \equiv \operatorname{Pr}^{i}\left[R_{t+1} \in k\right]=\operatorname{Pr}^{i}\left[\frac{I_{t+5}}{I_{t}}-1 \in k\right], \forall i
$$

The four panels ((a) - (d)) in Figure 3 below illustrate how do elicited probability density functions look like for a small subset of individuals:

Out of the 3,826 sample respondents, around $63 \%(2,406)$ meaningfully answered to the ex-

\footnotetext{
${ }^{5}$ We follow the standard convention in finance for long-horizon returns, and let $1+R_{t+1}(s)$ denote the stock market index gross return over $s$ periods ahead (hence the subindex $t+1$ ), which is equal to the product of the $s$ single-period (or yearly) returns:$$
1+R_{t+1}(s)=\prod_{f=0}^{s-1}\left(1+R_{t+1+f}\right)=\prod_{f=0}^{s-1}\left(\frac{I_{t+1+f}}{I_{t+f}}\right)
$$

Similarly, we let $1+R_{t}(s)$ denote the stock market index gross return over the most recent $s$ periods from date $t-s$ to date $t$ (hence the subindex $t$ ):

$$
1+R_{t}(s)=\prod_{b=0}^{s-1}\left(1+R_{t-b}\right)=\prod_{b=0}^{s-1}\left(\frac{I_{t-b}}{I_{t-1-b}}\right)
$$

See Campbell et al. (1997) for details.
} 


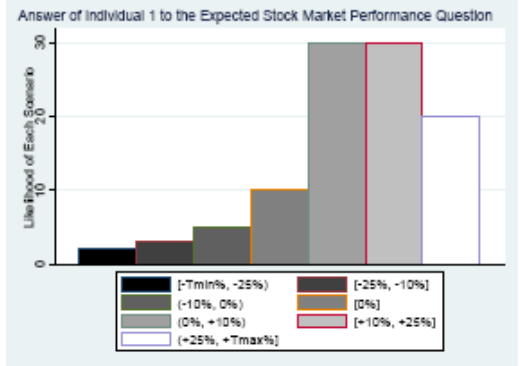

Panel (a): Individual 1.

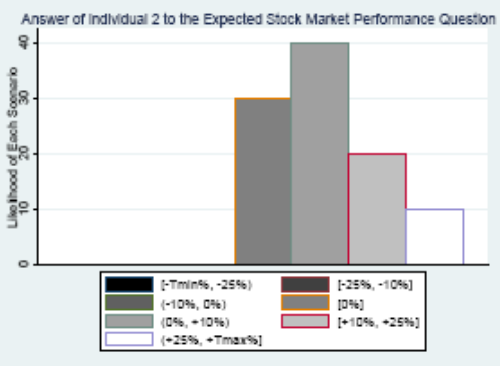

Panel (b): Individual 2.

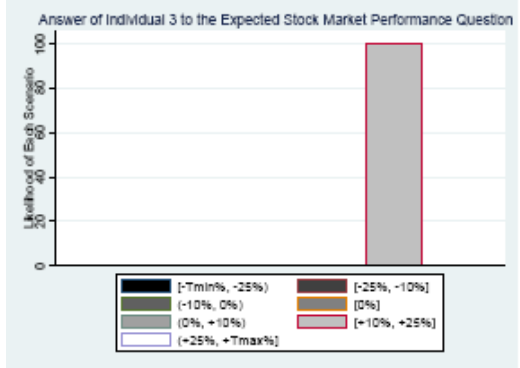

Panel (c): Individual 3 .

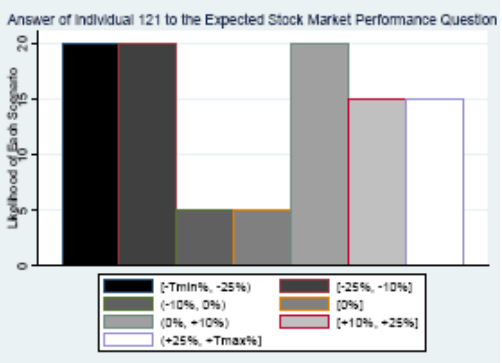

Panel (d): Individual 121.

Figure 3: Individual histograms of respondents' answers to survey question qc6 (PNR). Source: TNS 2007.

pectations question. 328 cases are excluded as the sum of their answers do not round up to $100 .^{6}$ Figure 4 below depicts the histogram, which averages the individual probability density functions of those who answered. On average, households appear more pessimistic and uncertain than the historical record would predict (Figure $2 \mathrm{~b}$ ).

To validate our survey data, and for comparison purposes, we construct from respondents' answers Dominitz and Manski's (1997) Positive Nominal Return (PNR) variable which captures the 5 -year ahead percentage chance of a positive nominal return ${ }^{7}$ :

$$
\forall i: \quad P N R^{i} \equiv \operatorname{Pr}^{i}\left[R_{t+1}(5)>0\right]=\operatorname{Pr}^{i}\left[\frac{I_{t+5}}{I_{t}}-1 \in \cup_{k=1}^{3}\{k\}\right]=p_{t+1,1}^{i}+p_{t+1,2}^{i}+p_{t+1,3}^{i}
$$

Figure 5 below, depicts the frequency distribution of responses, for ages in the 50-80 age bracket (panel (a)) and for all ages (panel (b)). Despite of the age differences, the similarities with both the

\footnotetext{
${ }^{6}$ Missing and erroneous answers are regressed against stockholding status, and a set of covariates (gender, marital status, education, risk preference) using a probit (Table 11 in the appendix). They appear strongly related to stockholding, just as Kézdi and Willis (2009) find for the HRS 2002 wave.

${ }^{7}$ In Dominitz and Manski (2007), 15,166 HRS respondents, aged 50 to 80 in 2004, were asked:

Positive Nominal Return (PNR): We are interested in how well you think the economy will do in the next year. By next year at this time, what is the percent chance that mutual fund shares invested in blue chip stocks like those in the Dow Jones Industrial Average will be worth more than they are today?

$$
\forall i: \quad P N R_{D M}^{i} \equiv \operatorname{Pr}^{i}\left[\frac{I_{t+1}}{I_{t}}-1 \in \cup_{k=1}^{3}\{k\}\right]
$$
}




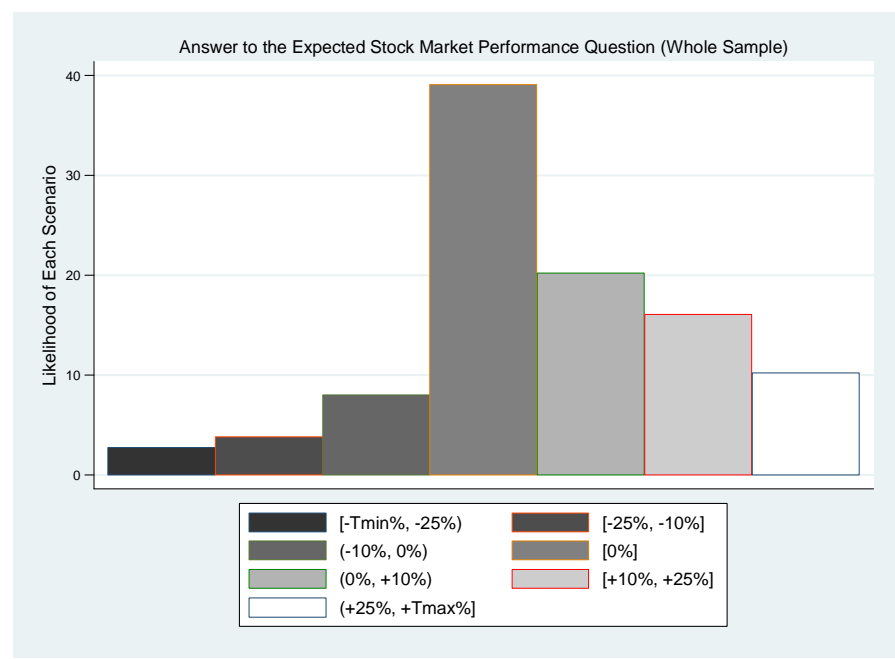

Figure 4: Histogram of average individual answers to the likelihood of the different scenarios regarding 5-year ahead stock market performance. Source: TNS 2007 survey.

HRS and the De Nederlandsche Bank Household Survey (DHS), exploited by Hurd et al. (2011), are striking: there is similar bunching of responses around round numeric probability answers. For all ages, the mean response is $46.5 \%$, while for the elderly, it is $47.1 \%$. This compares with a $49 \%$ mean response, for the 50-80 HRS 2004 respondents, and with a $41.6 \%$ (50.1\%) for a representative sample by age of the DHS 2004 (2006) respondents. However, bunching is much stronger in the $\{0,100\}$ answers, than in the 50 percent chance response, indicating less epistemic uncertainty according to Bruine de Bruin et al. (2000). For all ages, 31\% (21\%) gave answers consistent with absolute certainty that the index would go down (up) over the coming 5 years. Evidence from the financial literature on long horizon returns suggests that the longer time horizon given to evaluate stock market performance might explain the differences, because of mean-reversion (Campbell et al., 1997). In the next subsection we further examine this question.

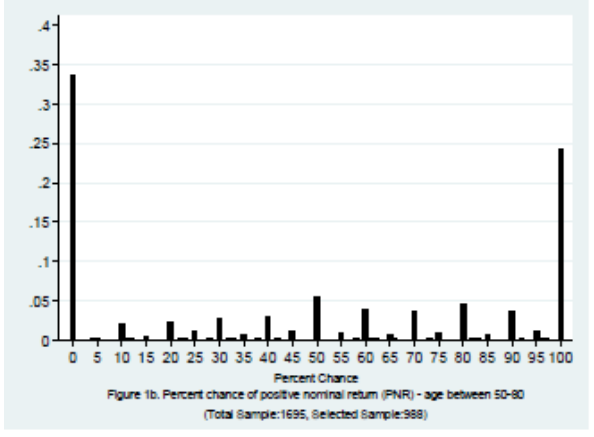

Panel (a): Ages 50-80.

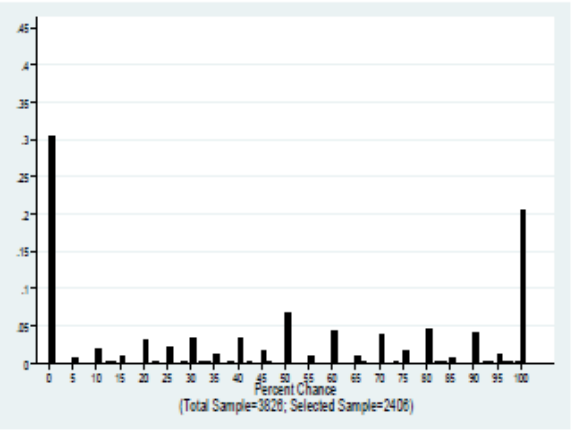

Panel (b): All ages.

Figure 5: PNR by age groups, frequency distribution. Source: TNS 2007.

Table 1 reports the distribution of responses and the response rate conditioning on age, gender, and marital and stockholding status. Consistent with the findings reported in Dominitz and Manski 
(2007), the mean percentage chance of a positive nominal return is higher for respondents who are married. The differential is 1.4 percentage points for men (50.1\% versus $48.7 \%)$, while for females, it is only 1.1 percentage points ( $43.7 \%$ versus $42.6 \%$ ). Figure 6 shows that also in France, males are more optimistic than females. Even when conditioning on marital and stockholding status and for all age brackets, men give more optimistic reports than do women, and are 6-7 percentage points more likely to give a response.

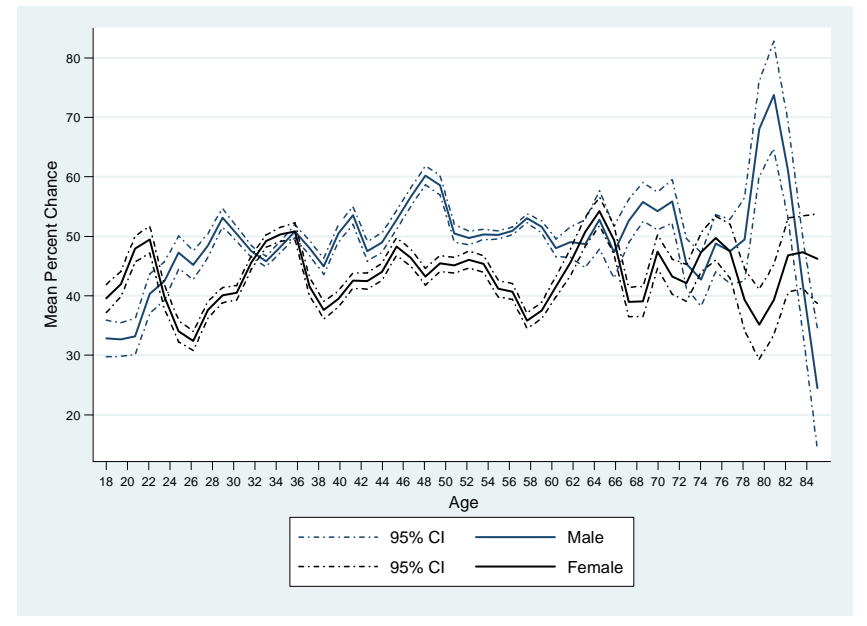

Figure 6: Mean PNR by age and gender. Source: TNS 2007.

In line with the HRS 2002 findings by Kézdi and Willis (2009), expectations (noisily) increase with the respondent's education and households' total wealth. Figure 7 (8) displays kernel-smoothed estimates of the mean percentage chance of a positive nominal return conditional on total wealth (educational attainement). The solid curve depicts point estimates and the grey area around it represents (bootstrap) 95\% confidence intervals. The median of total wealth is $€ 118,792$, and the 90th percentile $€ 413,476$. We excluded 42 households with wealth above $€ 800,000$. The richest households (with wealth above the 90th percentile), appear more optimistic regarding the future evolution of the stock market. An increase in wealth from the 10th to the 90th percentile, is estimated to increase the mean percentage chance of a positive nominal return by about 2 to 3 percentage points.

Figure 8 below compares by age, the mean percentage chance of a positive nominal return of respondents with some college education or more relative to those having at most completed high school. Broadly, the former seem to be slightly more optimistic than the latter, although both tend to become more optimistic regarding the future as they age.

Finally, expectations of a positive nominal return appear roughly hump-shaped in age, as does the response rate to the probabilistic question. In Figure 9, the mean response increases until the late 40s, when expectations reach its peak, only to decline from the mid 60s, although the pattern is very noisy with potential cohort effects present. The mean percentage chance of a positive nominal return is estimated to increase (fall) by about 8 to 12 ( 5 to 6 ) percentage points as age increases (decreases) from 20 to 50 (late 60s onwards). 


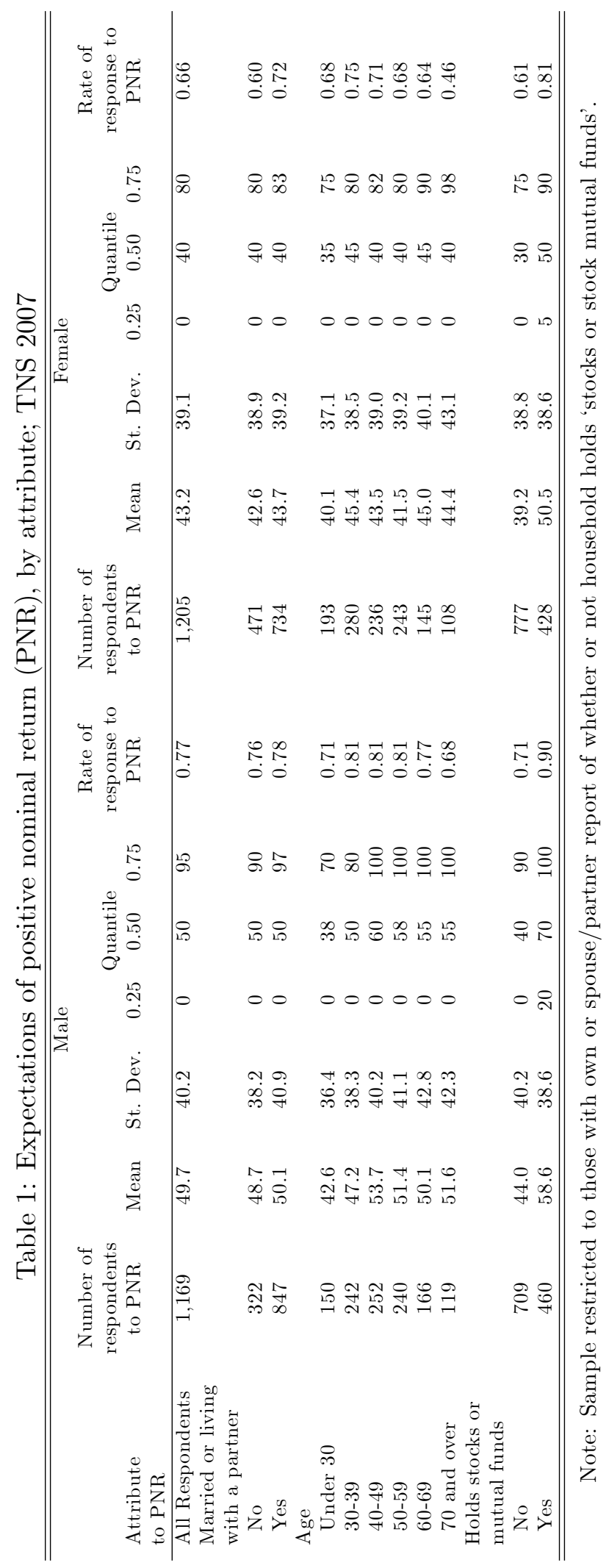




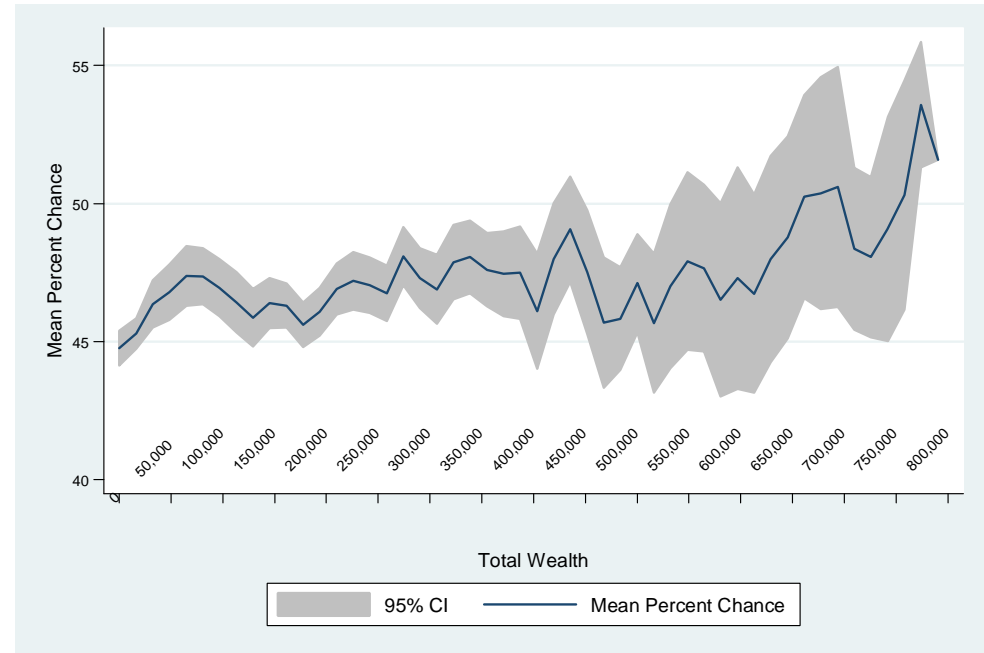

Figure 7: Mean percentage chance of a positive nominal return over the next 5 years (PNR) by total wealth. Source: TNS 2007.

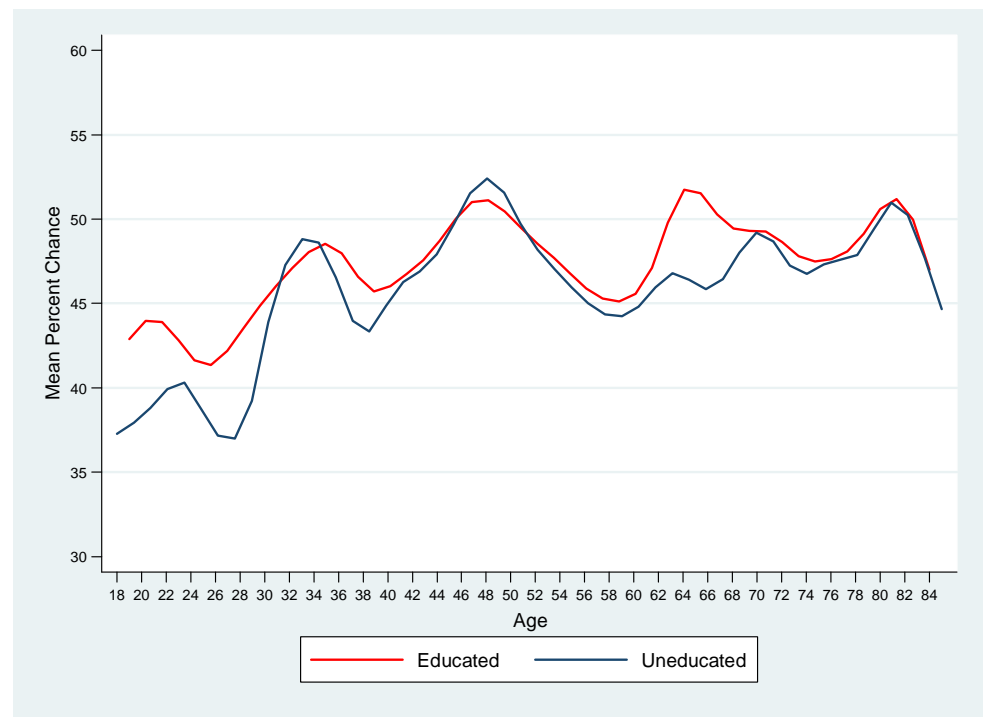

Figure 8: Mean percentage chance of a positive nominal return over the next 5 years (PNR) by educational attainement. Source: TNS 2007. 


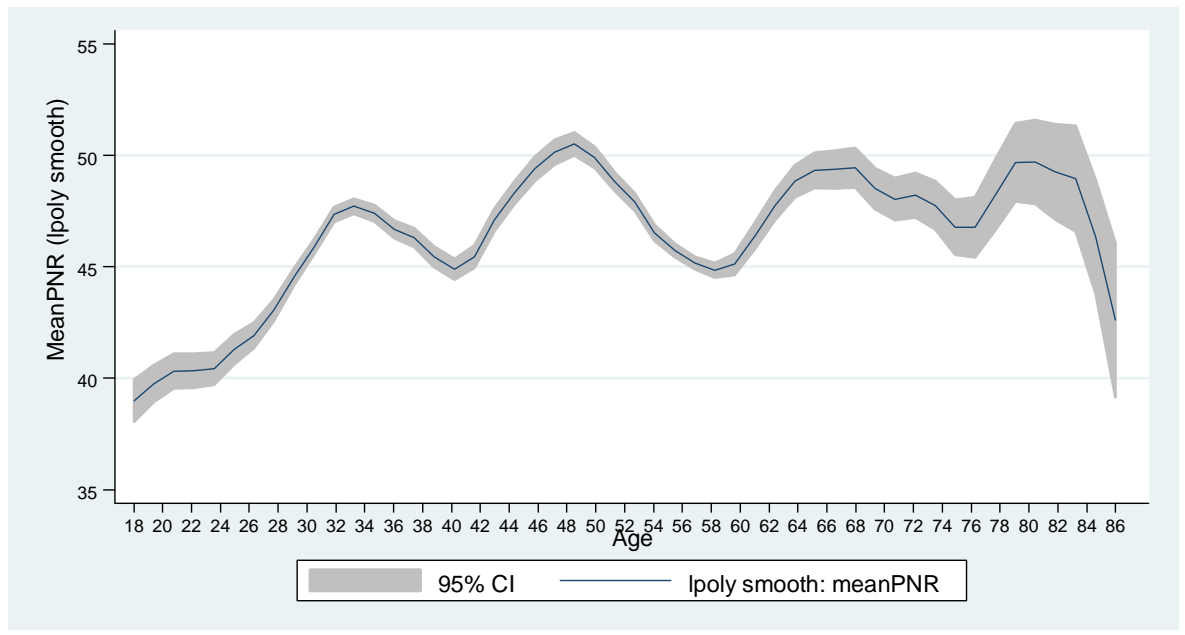

Figure 9: Mean PNR, conditional on age. Source: TNS 2007.

Standard life-cycle portfolio choice models predict that, conditional on being aware of the existence of a historical equity premium, the young should invest heavily in the stock market to take advantage and quickly accumulate wealth. The descriptive evidence reported here suggests that expectations vary systematically with age, and that both the young and the elderly appear particularly pessimistic. Although the evidence is consistent with existing findings for the elderly in the US, in France the young appear pessimistic rather than optimistic (Dominitz and Manski, 2011).

\subsection{Measuring Information}

Another possibility is that the young are particularly unaware of the investment opportunities offered by the stock market (King and Leape, 1987; Hurd, 2009). Recent studies stress the importance of financial literacy (reviewed in Lusardi, 2008) when accounting for stock market participation decisions. Those studies ask general numeracy questions as well as specific questions regarding elementary notions about the working of financial markets. Here, we are more specific and inquire respondents about recent past stock market performance, in line with the finance literature (e.g. Zhang, 2006).

To obtain a measure of how informed respondents were, we elicited probabilistically households' information sets, to capture: (i) differences in information across households, and (ii) the relationship between information about the recent past, and answers to forward-looking probability questions (Dominitz and Manski, 2011). In addition, conditioning on information reduces the bunching around focal point responses conveying absolute certainty, i.e. $P N R=\{0,100\}$.

In the TNS 2007, we inquired respondents about the likely evolution of the stock market index over the past five years, $I_{t-5}$, relative to the time of the interview (March 2007), $I_{t}$, as follows (translated wording):

C9. 'Over the past five years, do you think that the stock market... -For each category write down the likelihood of occurrence assigning a value between 0 and 100. The sum of all your answers must be equal to 
100-:

... has increased by more than $25 \%$

... has increased by 10 to $25 \%$

... has increased by less than $10 \%$

... has remained the same

... has decreased by less than $10 \%$

... has decreased by 10 to $25 \%$

... has decreased by more than $25 \%$

Question C9 inquires household $i$ about the subjective relative likelihood of occurrence, $p_{t, k}^{i}$, of each of the seven alternative scenarios, $k=1, \ldots, 7$. Each scenario represents a possible outcome range for the percentage change in the index between $t-5$ and $t, R_{t}(5) \equiv \frac{I_{t-5}}{I_{t}}-1$. Since ranges $k=1$ and $k=7$ are unbounded, we set $\left(R_{\max }, R_{\min }\right)$ to match observed values. The outcome ranges for $R_{t}$ are therefore identical to those of question C6 described above. Accordingly, households' subjective likelihoods are given by:

$$
p_{t, k}^{i} \equiv \operatorname{Pr}^{i}\left[R_{t} \in k\right]=\operatorname{Pr}^{i}\left[\frac{I_{t-5}}{I_{t}}-1 \in k\right], \forall i
$$

Five years prior to the time when the survey was conducted (March 2002), the stock market index was around half-way down the 'dot-com' bust. But, from the beginning of March 2002 (CAC $40=4688.02)$ until the beginning of March 2007 (CAC $40=5634.16)$, the index had increased an overall $20.2 \%$. Figure 10 below illustrates the wanderings of the CAC-40 index between 1987 and 2011:

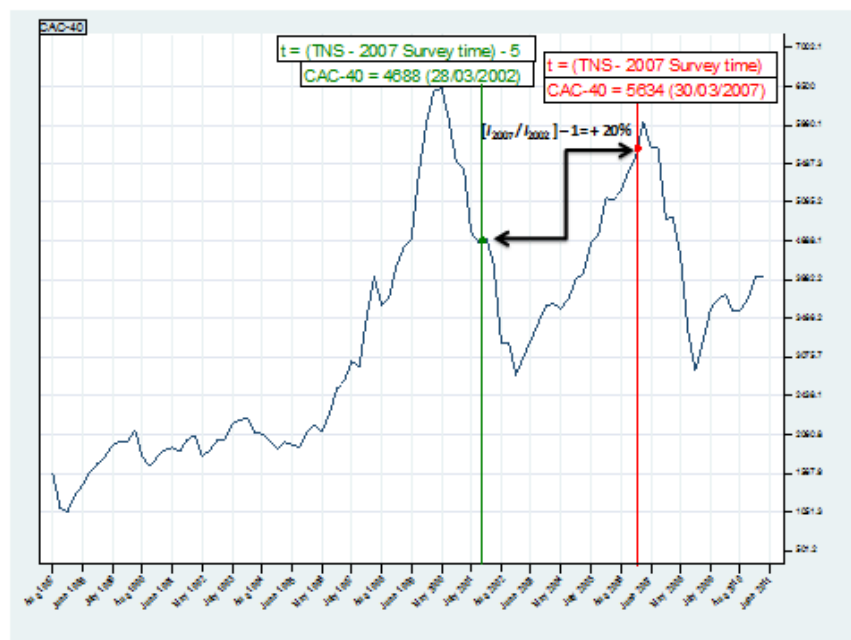

Figure 10: The French Stock Market Index CAC-40 between July 1987 and July 2011. Between March 2002 and March 2007 (5 years prior to the time of the survey) the index had increased by around $20 \%$. Source: Author's calculations from MSN Money monthly data, available online.

The panels (a) - (d) in Figure 11 below, illustrate how do individual information sets look like for the same small subset of individuals whose answers regarding future stock market performance 
are depicted in Figure 3, panels.(a) - (d). Information regarding past stock market performance is elicited as a probability density function. According to Figure 10, a perfectly informed individual should attribute probability one to the outcome range "...has increased by 10 to $25 \% "(k=2)$, higlighted in red below:

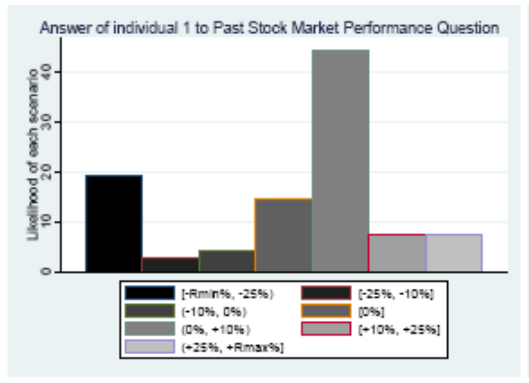

Panel (a): Individual 1.

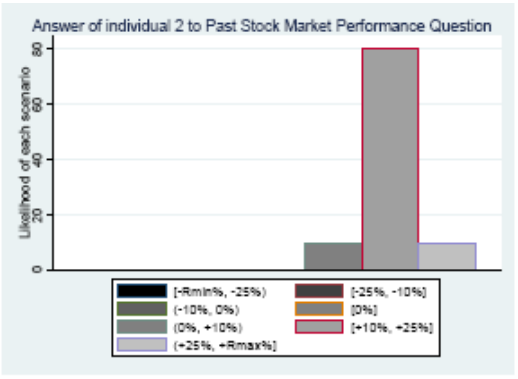

Panel (b): Individual 2.

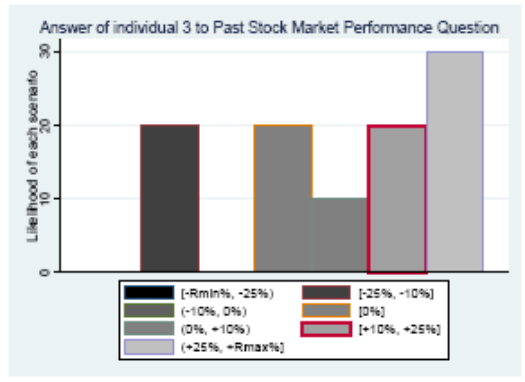

Panel (c): Individual 3

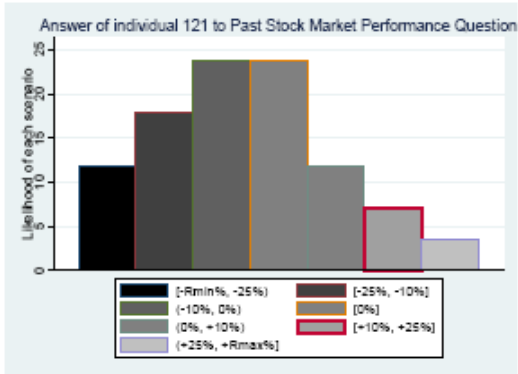

Panel (d): Individual 121.

Figure 11: Individual histograms of responses to the survey question C9 (pPNR). Source: TNS 2007.

Out of the 3,826 sample respondents, around $59 \%(2,253)$ provided a meaningful answer to the information question. 322 cases are excluded as the sum of their answers do not round up to 100 $[95,105]$. Figure 12 below depicts histogram of the average of the individual probability density functions.

A striking finding is that households are on average also pessimistic regarding how well has the stock market performed over the last five years. Although this might be due to imperfect recall given the unusually long horizon (although respondents were given enough time to access the internet or else, and report the correct response) it might also be related to the 'dot-com' bust being overweighted on respondents' memory (Hurd et al., 2011), even if outside the time frame given in the question. Table 2 below reports summary sample statistics for respondents' answers regarding past and future stock market returns, imposing a uniform distribution within the different outcome ranges. Although the big spread around the past sample average returns came as no surprise (possibly indicating ambiguity), it is remarquable that it remains smaller than the spread around the mean future stock market performance:

For consistency, we construct from respondents' answers the past Positive Nominal Return (pPNR) variable which captures the percentage chance of a positive nominal return over the last 


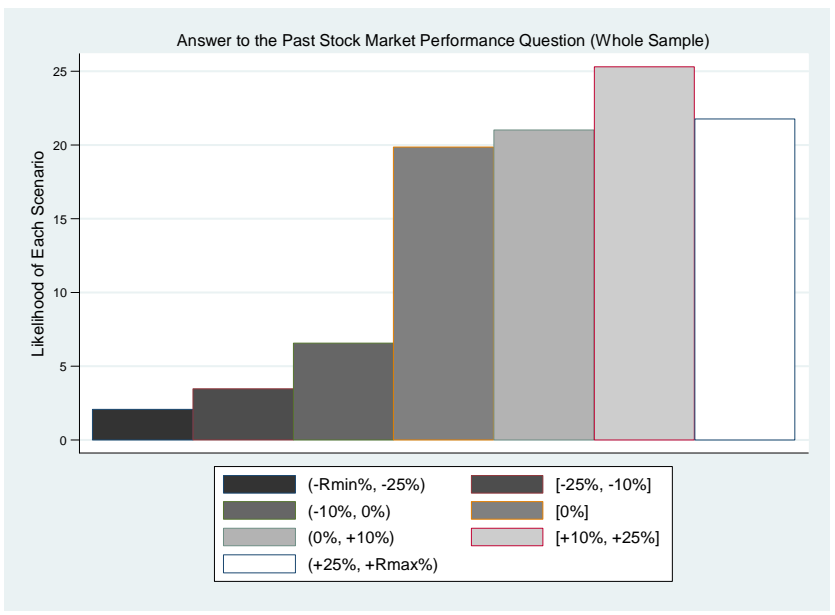

Figure 12: Histogram of average individual answers to the relative likelihood of the different scenarios regarding the stock market performance over the last 5 years. Source: TNS 2007.

Table 2: Sample Moments from Questions QC6 (expected stock market performance) and QC9 (past stock market performance); TNS 2007.

\begin{tabular}{lccccc}
\hline \hline Variable & No obs. & Mean & Std. Dev. & Min & Max \\
\hline Expected Return (ER) & 2460 & 0.055311 & 0.112602 & -0.625 & 1.125 \\
Std. Dev. of ER & 2460 & 0.068028 & 0.07347 & 0 & 0.43056 \\
Past ER (pER) & 2231 & 0.11938 & 0.139876 & -0.375 & 0.375 \\
Std. Dev. of pER & 2231 & 0.065598 & 0.069211 & 0 & 0.375 \\
\hline \hline
\end{tabular}


five years:

$$
\forall i: \quad p P N R^{i} \equiv \operatorname{Pr}^{i}\left[R_{t}(5)>0\right]=\operatorname{Pr}^{i}\left[\frac{I_{t-5}}{I_{t}}-1 \in \cup_{k=1}^{3}\{k\}\right]=p_{t, 1}^{i}+p_{t, 2}^{i}+p_{t, 3}^{i}
$$

In Figure 13, we depict the frequency distribution of responses to pPNR for all ages. As previously, there is bunching of responses around round numeric probability answers indicating that rounding is not specific to forward looking questions but rather, to respondents rounding when confronted with the probabilistic elicitation format. For all ages, the mean response is $68 \%$, while the true answer is a $100 \%$ chance of a positive nominal return over the last 5 years. Around $44 \%$ of sample respondents (990 individuals) gave the correct answer:

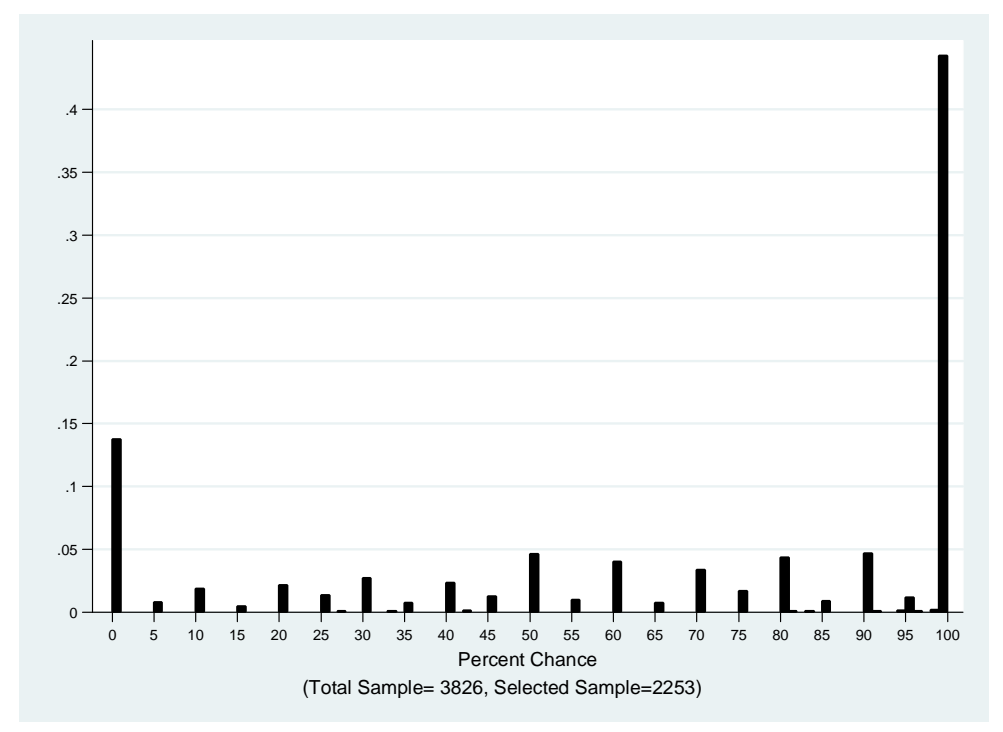

Figure 13: Percentage chance of a Positive Nominal Return over the past five years (pPNR) for all ages, frequency distribution. Source: TNS 2007.

In Figure 14 we examine what type of information had those respondents who were absolutely certain regarding the future evolution of the stock market (panel (b), Figure 5). Panel (a) shows that amongst those who were absolutely certain that the stock market would go down $(24 \%, 567$ answered $\mathrm{PNR}=0 \%$ ), around $35 \%$ were absolutely certain that it had not increased over the last 5 years, while $43 \%$ were absolutely certain that it had gone up. Around $5 \%$ gave a 50 percent chance of either going up or down. This contrasts with panel (b), for respondents who were absolutely certain that the stock market would go up (21\%, 446 answered PNR=100\%): 83\% were absolutely certain that the stock market had gone up, while only $6 \%$ gave answers consistent with absolutely certainty of the stock market having gone down. Only $2 \%$ gave a 50 percent response. Hence, individual information about the past significantly contributes to unbundle the bunching on responses conveying absolute certainty regarding the future, which are clearly wrong, and provides an additional source of heterogeneity amogst respondents.

Table 3 reports the distribution of responses and the response rate conditioning on age, gender 


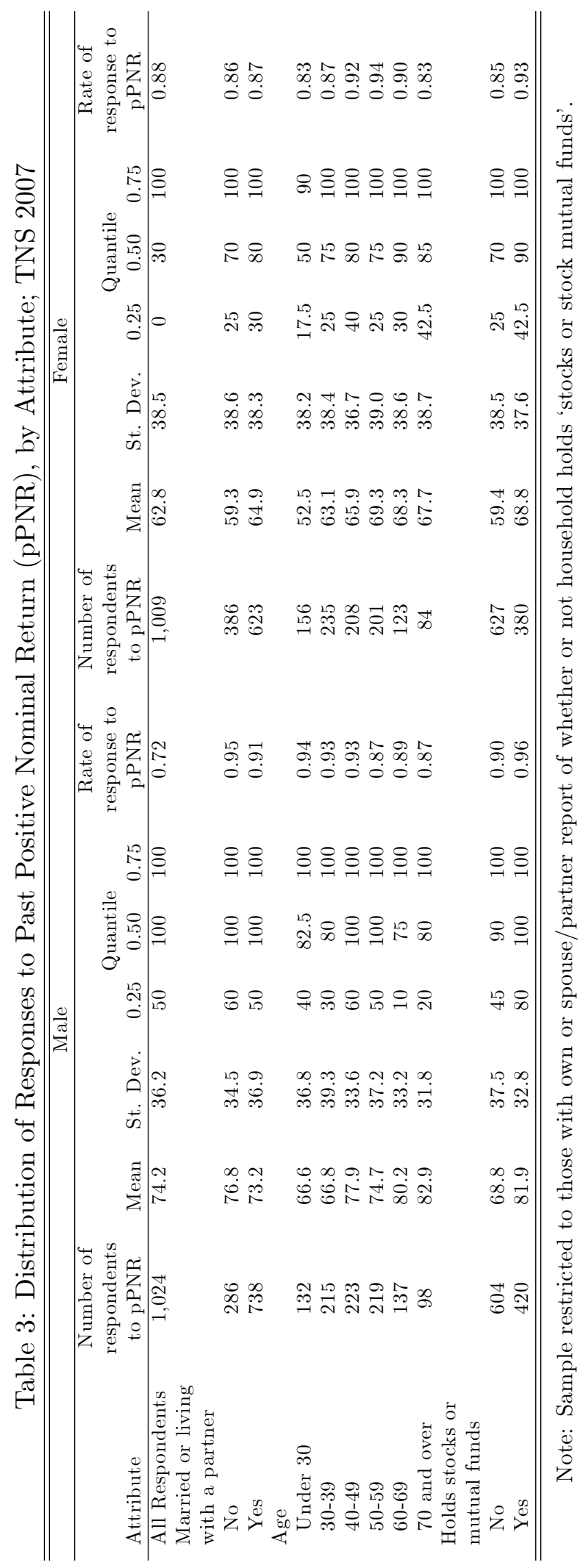




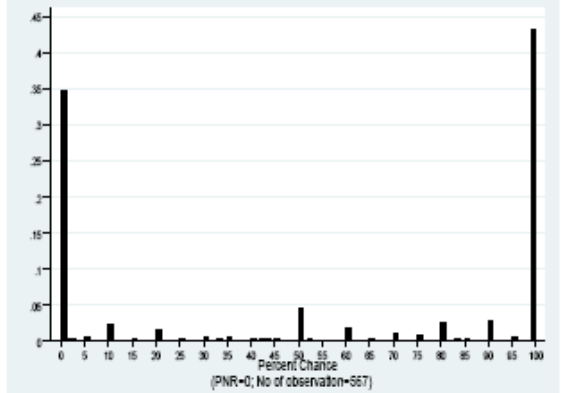

Panel (a): How much do pessimists know? pPNR conditional on $\mathrm{PNR}=0 \%$.

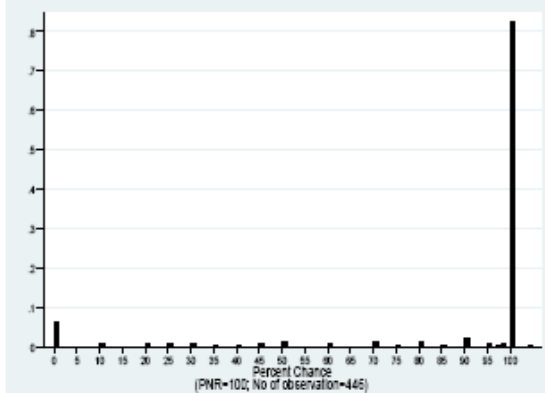

Panel (b): How much do optimists know? pPNR conditional on $\mathrm{PNR}=100$.

Figure 14: pPNR conditional on PNR, for pessimists (a) and optimists (b), frequency distribution. Source: TNS 2007.

and stockholding status. Since over the five-year time frame given to respondents, the CAC 40 index had increased by $20.2 \%$, an informed respondent should have given an answer of $p P N R^{i}=100$ percent. In accordance with the findings reported by Lusardi (2008) on the financial literacy of US adults, male respondents who are older, single and stockholders report higher mean (and lower standard deviations of) percentage chances of a past positive nominal return. The differential is 11.4 percentage points higher for men than for women. Although information broadly increases with age, irrespective of gender, the uncertainty of the reports decrease with age for males, while for females, remains broadly constant. Stockholders report a higher mean by about 10 percentage points, and are around 6 percentage points more likely to give a response. Figure 15 shows that males are broadly better informed than females:

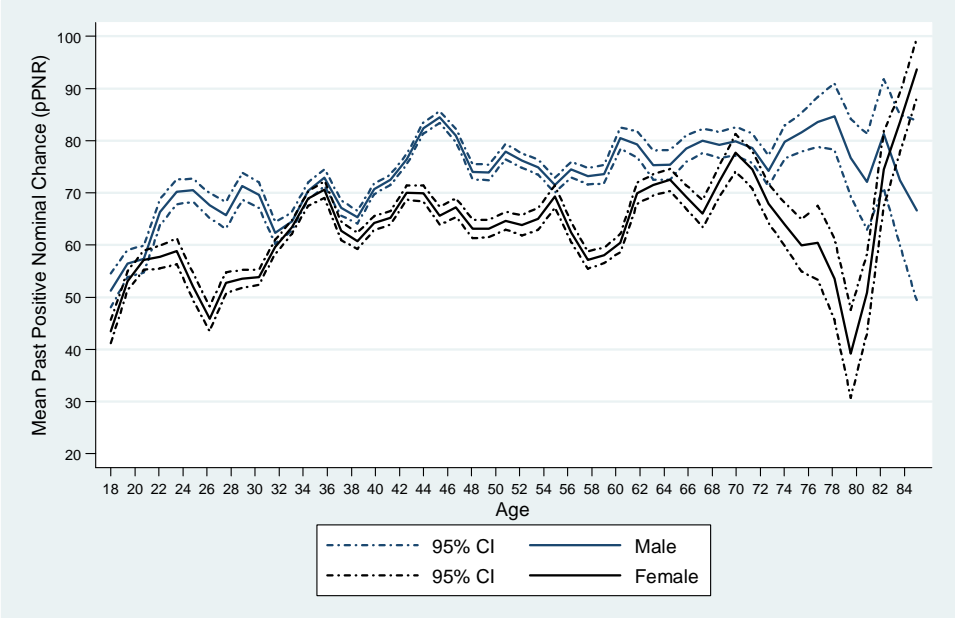

Figure 15: Mean percentage chance of a positive nominal return over the last 5 years (pPNR) by age and gender. Source: TNS 2007.

Information about past stock market performance broadly increases with age until the mid 


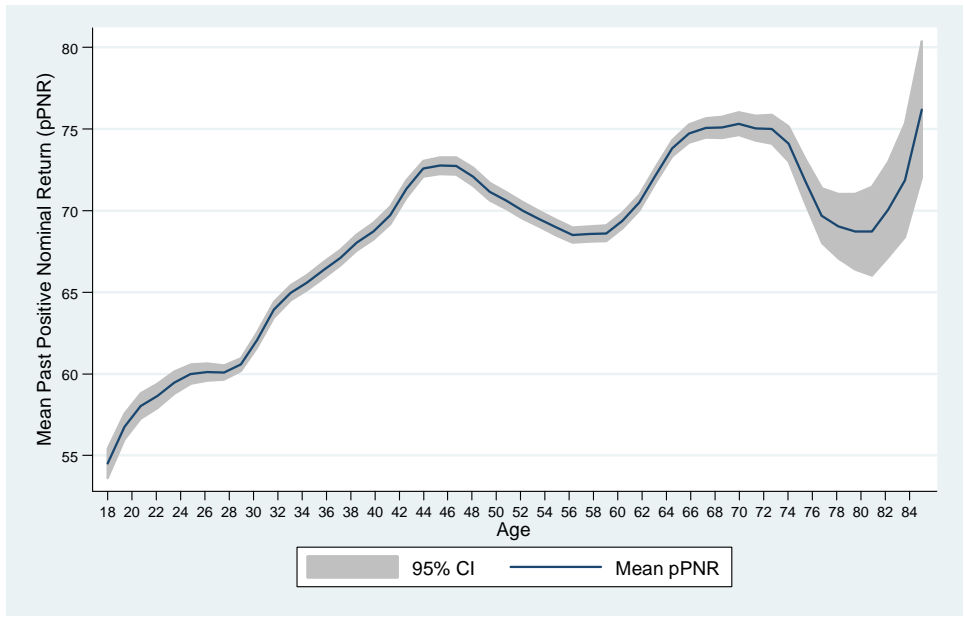

Figure 16: Mean percentage chance of a positive nominal return over the last 5 years (pPNR) by age. Source: TNS 2007.

70s, and then decreases, although the point estimates are much noisier. Figure 16 presents kernelsmoothed estimates of the mean percentage chance of a past positive nominal return conditional on age. The mean percentage chance of a past positive nominal return is estimated to increase (fall) by about 20 to 22 (10 to 12) percentage points as age increases until (decreases after) 75 . In line with King and Leape's (1987) conjecture, figure 16 suggests that respondents build an "informational stock" slowly through the life-cycle, which depreciates by the end of it. This process of lifecycle information accumulation may thus account for the identified pessimism amongst the young and the elderly regarding the future performance of the stock market, providing support to Van Nieuwerburgh and Veldkamp's (2010) basic interplay between expectations and information sets.

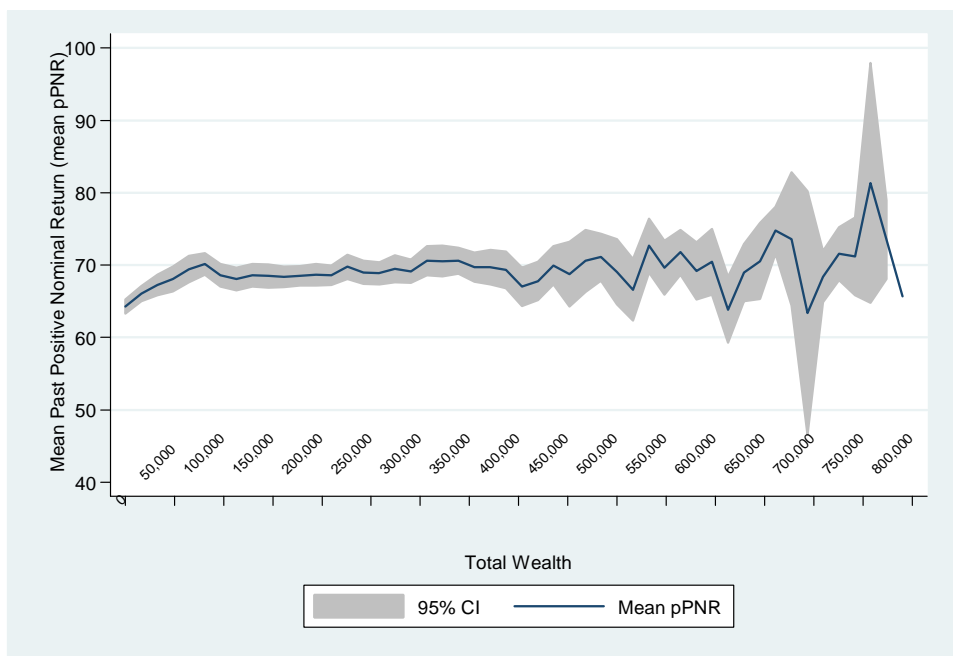

Figure 17: Mean percentage chance of a positive nominal return over the last 5 years (pPNR) by wealth. Source: TNS 2007.

Figure 17 shows that information increases until the 50th percentile of wealth $(€ 118,792)$, 
remains roughly constant until the 90th percentile (€413,476), only to increase again albeit very heterogeneously. The richest households (with wealth above the 90th percentile), may thus be more optimistic (and disagree more) regarding the future investment opportunities because they are better (and more heterogeneously) informed. ${ }^{8}$ Relative to non-participation amongst the richest, and in line with Guiso and Jappelli (2005), heterogeneity in stock market information appears as a different alternative to social interactions (Hong et al., 2004; Guiso et al., 2008), better private investment opportunities (Heaton and Lucas, 2000) or taxation (Poterba, 2002).

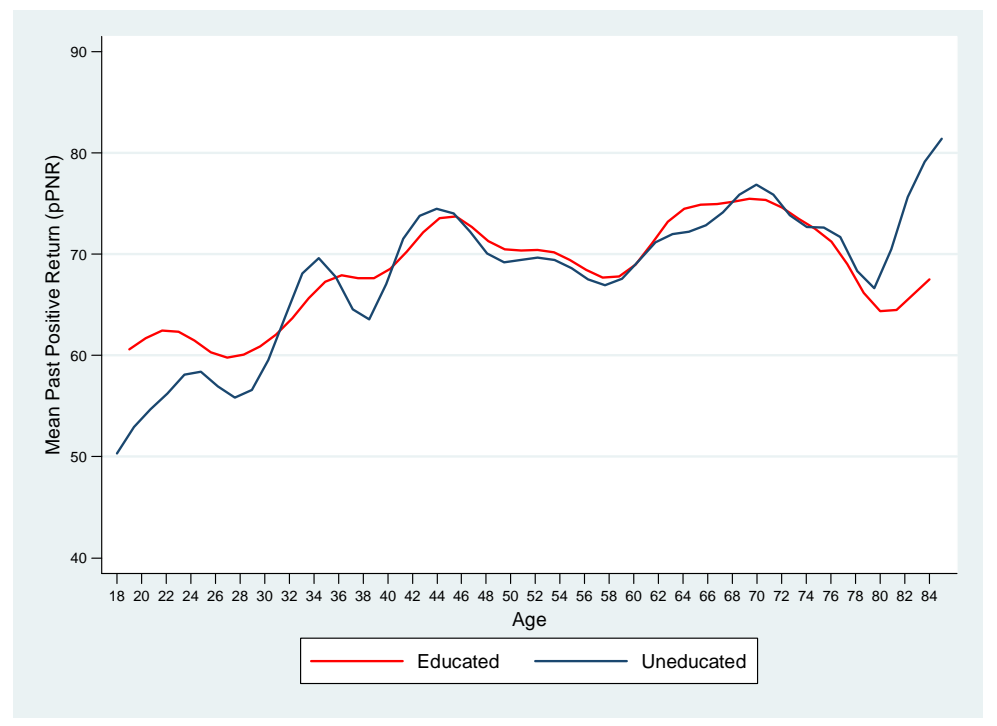

Figure 18: Mean percentage chance of a positive nominal return over the last 5 years (pPNR), by education. Source: TNS 2007.

Surprisingly, information about past stock market performance does not increase with own's educational attainement, although it broadly increases with age within educational groups (Figure 18). Table 4 below reports estimation results of a two-way censored Tobit specification for answers to question qc9 (censored below by '0' and above by '100'), as a function of age, gender, sources of advice (friends, family, professional, broad media, specialised media) and information (TV, economics/finance emissions), own and parents' educational attainment, family background (middle/lower/other class), endowments (income and wealth), financial decision taking (no/partial/complete delegation of financial decisions), own past experience ('frequency of recent trades'), preferences (risk aversion and impatience), constraints in accessing information ('online banking') or of inertia in information sources (parents' stockownership status, 'cultural transmission'), and of the tightness of households' budget constraint ('importance of money in life').

Categorical answers to frequency, variety and access specialised media, advice from professionals, as well as the number of stock market transactions carried over the last year, increase the likelihood of being informed. ${ }^{9}$ Interestingly, parents' stockownership status ('cultural transmission'), parents'

\footnotetext{
${ }^{8}$ However, the increased heterogeneity in information for the richest might just be a small sample problem, since only 272 respondents answered to the information question.

${ }^{9}$ The positive and significant effect of access to specialised media and professionals' advice on households' infor-
} 
Table 4: The Determinants of Past Positive Nominal Return (pPNR); TNS 2007

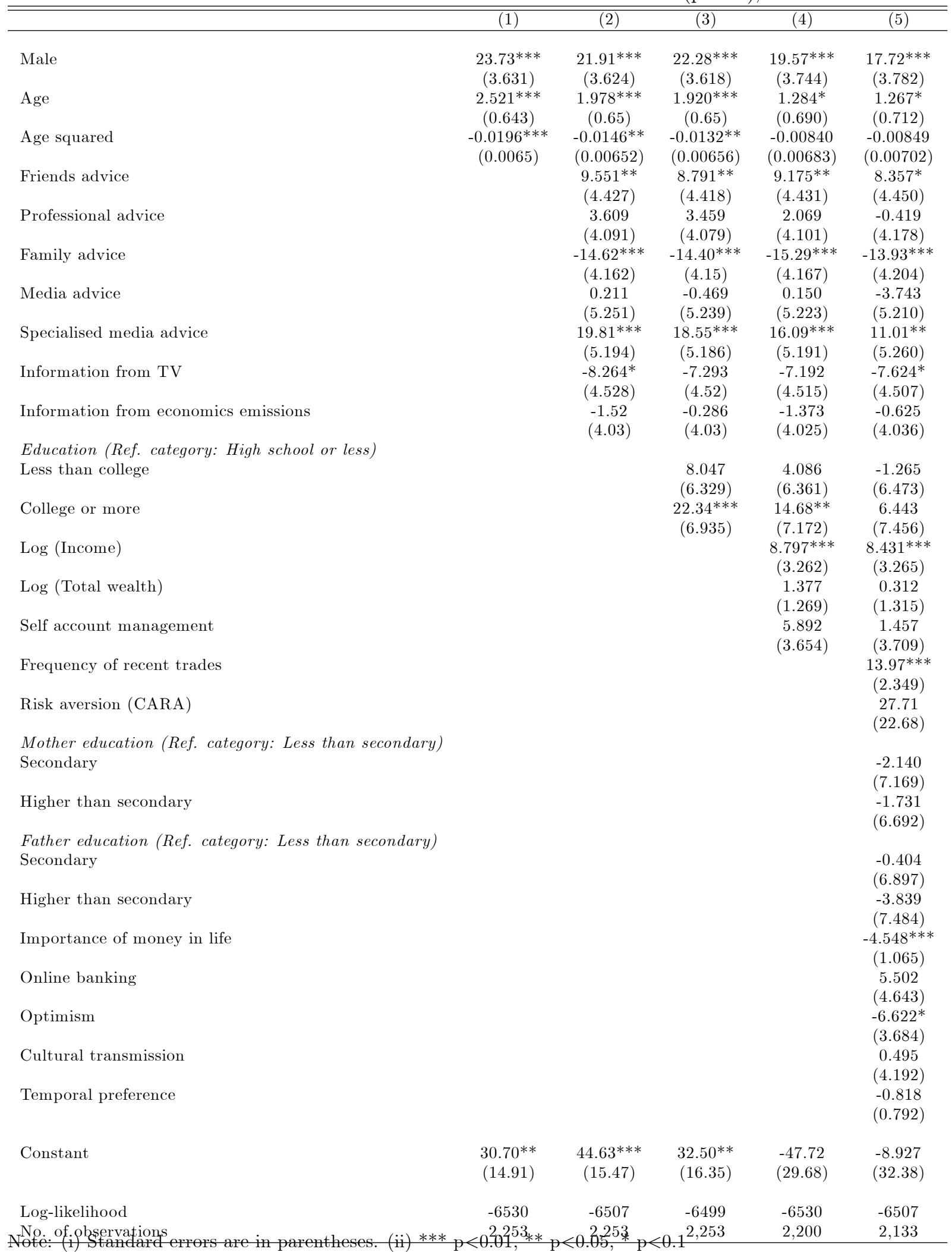


educational attainment or family background (omitted from the table) do not increase the odds of being informed, and actually significantly decreases them for those who follow 'family advice'. Since those who follow 'friends' advice' are more likely to be informed, we interpret it as being consistent with social interactions being instrumental in gathering information (Hong et al., 2004). On the other hand, a measure of optimism ('being lucky in life') has a negative impact on being informed, indicating that an 'overconfidence bias' is not present once gender is conditioned upon: although males appear better informed, supporting more optimistic forward looking expectations, optimists appear consistently worse informed. This may help reconciling Bilias et al.'s (2010) findings consistent with inertia in households' portfolios, with Guiso and Jappelli's (2006) fidings consistent with excess trading even amongst the general population. We do not find evidence of either temporal or risk preferences determining information sets, in line with Van Nieuwerburgh and Veldkamp (2010). ${ }^{10}$ Although total wealth does not increase the odds of being informed, income does (even if we condition on the number of stock market operations carried over the last year), in line with a costly information acquisition interpretation (Peress, 2004). ${ }^{11}$

Overall, these findings are consistent with financial information being slowly acquired through the life-cycle (King and Leape, 1987) from own past experience, from others (social interactions) and from specialised media. On the other hand, the negative effect of the 'importance of money in life', which scores higher the poorer and the more financially constrained the respondent is, reveals a novel aspect in information acquisition: disenfranchisement. Notice that the negative impact of both disenfranchisement and optimism is consistent with rational inattention theory (Sims, 2003).

\section{Subjective Expectations, Information and Stock Market Partic- ipation}

An important puzzle in the literature is why so few households hold stocks (Haliassos and Bertaut, 1995). Although, in an expected utility framework, the standard two-risky asset model predicts that decision takers invest in the risky asset if and only if its expected return exceeds the return of the riskless asset (Arrow, 1965; Merton, 1969; Samuelson, 1969), only recently have researchers started to collect data on subjective expectations of stock market returns. ${ }^{12}$ Accordingly, here we examine the extent to which subjective expectations determine households' stock ownership decision, conditioning on what they know.

mation is consistent with the existence of a market for financial information, where quality is priced, i.e. the vertical differentiation component in Cabrales and Gottardi's (2011) analysis.

${ }^{10}$ Our measure of temporal preference is inversely proportional to "impatience", or how far-sighted the respondent is, rather than a preference for an early resolution of uncertainty. Hence, our results are consistent with Van Nieuwerburgh and Veldkamp (2010), who find that risk aversion does not determine the demand for information.

${ }^{11}$ In unreported regressions, we estimated an ordered probit on the number of stock market operations carried over the previous year (grouped in 5 categories), and find evidence consistent with wealth and income increasing the number of trades, but also with liquidity and borrowing constraints forcing households to trade at the extensive margin. These results are available upon request.

${ }^{12}$ In particular, the decision to invest in the stock market does not depend on either preferences, endowments or information about past stock market performance: just on the subjective expected return. Further details are provided in the elementary theory section of the appendix. 
To obtain subjective expectations from answers to the probability question $\left(\mathrm{PNR}^{i}\right)$, Dominitz and Manski (2007) show that if (i) stock market returns are normally distributed, with cdf. $\Phi($.$) :$

$$
P N R^{i}=\operatorname{Pr}^{i}\left[R_{t+1}(5)>0\right]=\operatorname{Pr}^{i}\left[\frac{R_{t+1}(5)-\mu_{i}}{\sigma_{i}}>-\frac{\mu_{i}}{\sigma_{i}}\right]=1-\Phi\left(-\frac{\mu_{i}}{\sigma_{i}}\right)
$$

and if (ii) a common variance is assumed, $\sigma_{i}=\sigma$ (for example, equal to the value obtained from historical records), then:

$$
\mu_{i}=-\sigma \Phi^{-1}\left(1-P N R^{i}\right)
$$

meaning that respondents reporting a higher percentage chance that the stock market will increase over the next five years $\left(P N R^{i}\right)$, have a higher subjective mean return expectation $\left(\mu_{i}\right)$, and should then be more likely to invest in the stock market. ${ }^{13}$

To obtain a measure of stock ownership, question qc19 in the TNS 2007 inquires respondents about the different types of financial instruments and accounts they hold, and in particular whether they invest in the stock market either directly or indirectly. We define direct stockholdings as the sum of stocks of privatised public companies, listed stocks of private companies and stocks of foreign firms held. Indirect stockholdings are those held through mutual funds and managed investment accounts. ${ }^{14}$ The proportion of households who hold stocks directly is $22 \%$, and $37 \%$ either directly or indirectly. Although low, the participation rates are slightly higher than those obtained from previous past surveys ${ }^{15}$ and similar to the figures reported by Haliassos (2008) for other countries at that time. In Figure 19, stock market participation amongst respondents displays a clear humpshaped pattern by age:

The literature on household finance has found that those who are better educated, older and wealthier, are more likely to hold stocks. Dominitz and Manski (2007) reported that the probability of holding stocks increased with the perceived chance of a positive return of investing in the stock market amongst the elderly. ${ }^{16}$ Since subjective expectations have been found to systematically vary with risk preferences, information, and demographic and socio-economic characteristics, here we estimate the conditional effect of the percentage chance of a positive nominal return on stockholdings for a representative sample by age and wealth.

\footnotetext{
${ }^{13}$ Since we inquire about a longer investment horizon, we exploited monthly data on the CAC 40 stock market index between July 1987 and July 2011 (230 observations) to compute the standard deviation of five-year log returns to be 0.19 . When inserted into the above expression, the sample average percentage chance of a positive nominal return of 46 percent (reported in the appendix, Table 11) corresponds to a sample mean expected return of 0.019, about five times smaller than the historical mean of 0.108 . A respondent reporting a value of $P N R^{i}=72$ percent, would match the rational expectations prediction of 0.108 .

${ }^{14}$ We exclude both government bonds and homeownership from the risky asset category, even if the latter are highly illiquid and indivisible (and therefore risky), because French households mostly buy houses for the flow of services they provide rather than as a financial investment. Still, in the estimation we control for the level of total net worth (real plus financial) and include a dummy variable that takes value one when home-ownership status is observed.

${ }^{15}$ For the 35-55 year-olds corresponding subsample in the Patrimoine 1998 INSEE survey, the proportion of households holding risky assets 'directly' is 21.6 and either directly or through mutual funds, 32.4.

${ }^{16}$ Table 11 (Table 12) in the appendix shows a similar qualitative pattern emerges for the elderly (all ages) in the TNS 2007, consistent with their findings and theoretical predictions.
} 


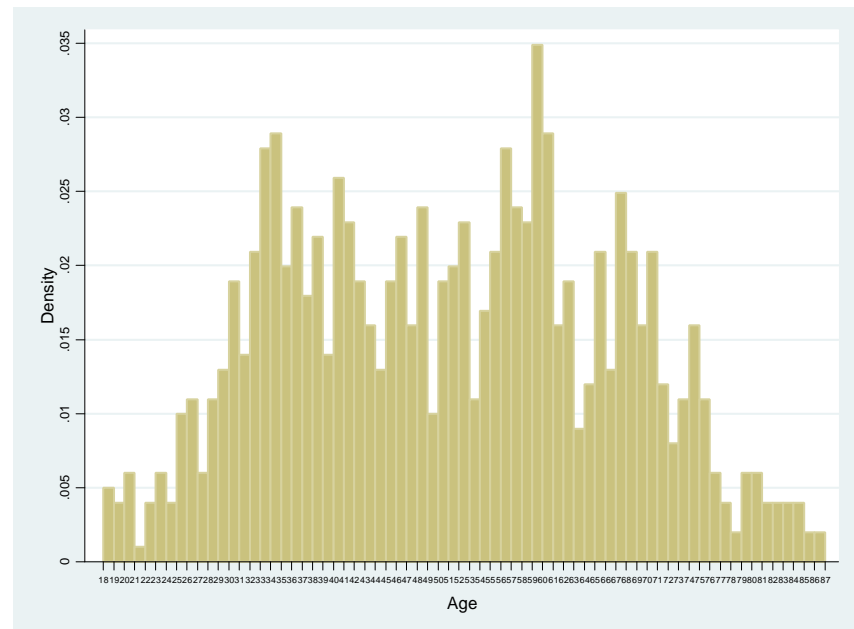

Figure 19: The probability of holding stocks and stock mutual funds, by age. Source: TNS 2007.

Conditioning on individual information is important for both theoretical and empirical reasons. Theoretically, households form their expectations conditioning upon their individual information sets, $I^{i}$. Although in the rational expectations tradition $I^{i}$ would be much larger, here we proxy it by the individual degree of knowledge of only the most recent stock market return realization over the relevant horizon, $I^{i}=\left\{R_{t}(5)\right\} .{ }^{17}$ Empirically, Dominitz and Manski (2011) conjecture that differences in the way people use public information may explain much of the observed heterogeneity in subjective expectations, $\mu_{i}$. They find that "A plurality, but not a majority, of persons revise their expectations in the direction predicted by the persistence model of behavioral finance." The persistence model maintains that recent stock market performance will persist into the near future. Our information measure $p P N R^{i}$ precisely measures the extent to which respondents know about recent past stock market performance.

We estimate households' probability of holding stocks $\operatorname{Pr}\left(s_{t}^{i}=1 \mid p_{t+1}^{i} ; p_{t}^{i} ; \mathbf{x}_{i}\right)$ as a function of the percentage chance of a positive nominal return $\left(p_{t+1}^{i} \equiv P N R^{i}\right)$, conditioning on information $\left(p_{t}^{i} \equiv p P N R^{i}\right)$, and a vector of observables $\mathbf{x}_{i}$, which contains measures of time and risk preference (discount factor, risk aversion), endowments (income and total wealth), household constraints (liquidity constraint, access to online banking), demographics (age, gender and marital status) and inertial factors (who takes financial decisions, stocks in pay or cultural tasnmission, which records whether the respondent's parents are stock owners) which have been found in the literature to matter at the extensive margin:

$$
\operatorname{Pr}\left(s_{t}^{i}=1 \mid p_{t+1}^{i}, p_{t}^{i} ; \mathbf{x}_{i}\right)=\mathbf{\Phi}\left(\delta_{t+1} p_{t+1}^{i}+\delta_{t} p_{t}^{i}+\boldsymbol{\delta}^{\prime} \mathbf{x}_{i}\right)
$$

where $\mathbf{\Phi}($.$) denotes the standard normal cumulative distribution function, since we assume that$

\footnotetext{
${ }^{17}$ In the rational expectations tradition, $I^{i}$ includes knowledge of the data generating process of stock market return realizations, as well as of the true economic model compatible with such data generating process. Typically, it is assumed to be $I^{i}=\left\{R_{t}(5), R_{t-1}(5), \ldots\right\}=I, \forall i$. But see Guesnerie (1992) for a thorough analysis of the necessary knowledge to form rational expectations.
} 
there is and unobserved error term $e_{t}^{i}$ normally distributed. Table 11 in the appendix reports descriptive statistics for the main variables, for the whole and the selected samples.

The results of the probit estimation are reported in Table 5, for all ages. The variables have the expected signs with minor differences across columns ${ }^{18}$, confirming the robust effect of subjective expectations on the probability of holding stocks. A 1 percent increase in the percentage chance of a positive nominal return (corresponds to an 10 percent increase in the sample expected return,i.e. from $1.9 \%$ to $2.1 \%$ ) increases the probability of holding stocks by $0.001 \%$, which corresponds to an increase of $0.1 \%$ in the unconditional probability (from $37.5 \%$ to $37.6 \%$ ). ${ }^{19}$ Notice that the positive effect of information remains statistically significant once heterogeneity in either preferences, decision taking or constraints is taken into account, but that when omitted (column 6), it biases upwards the estimated effect of expectations on stockownership.

If capital markets are imperfect (transaction or informational costs) households' income and wealth influences portfolio choice. ${ }^{20}$ The empirical analysis reveals that their effect is best captured by a second order polynomial, which facilitates the comparison with existing results in the literature (Guiso et al. (2003) or King and Leape (1998)). Total wealth has a positive effect on participation and is significant at the $1 \%$ level. An increase in total wealth from the first decile (6,300 euros) to the ninth decile (450,000 euros) increases the probability of participation by $9 \%$. Income also increases the probability of participation in the stock market: moving from the first to the ninth decile increases the probability of stockownership by $13 \%$. The effects are consistent with fixed transaction and information costs of accessing the stock market, as well as of decreasing aversion to financial risk taking, since both capture households' initial endowments other than housing.

Although previous empirical studies also find that education increases the probability of participation, most of them interpret its effect as a proxy for information. Since we have a very good direct measure of how informed respondents are regarding the stock market, holding a college degree (or further) does not significantly increase the probability of participation, relative to those who hold only a high school diploma or less.

Management variables also appear important: although those who take financial decisions by themselves are less likely to participate relative to those who totally or partially delegate in a financial advisor, the effect is not statistically significant (but see Table 9 below). But those who manage their accounts online (online banking) are around 11 percent more likely to participate, and if respondents' parents are stock owners themselves ('cultural transmission'), they are 16 percent more likely to own stocks. Since Table 4 reports that neither significantly increases the odds of being informed, we interpret these effects as inertial factors.

Also, measures of preference heterogeneity are important and consistent with recent economic

\footnotetext{
${ }^{18}$ Results in Table 3 only refer to direct and indirect stockownership. But the sign and magnitude of the reported estimates are robust to changes in the definition of stockownership (only direct stockholders). They are also robust to a semi-log specification in income and financial wealth.

${ }^{19}$ Although the effect appears quantitatively small, it is not. See Hurd et al. (2011), Kezdi and Willis (2009) or Arrondel et al. (2011) who, instead of working with the subjective probability of a positive nominal return $\left(P N R^{i}\right)$, introduce as regressors the first and second moments $\left(\mu^{i}, \sigma_{i}\right)$ of the individually elicited distributions.

${ }^{20}$ See King and Leape (1998) and simulated results by Cocco et al. (2005) or Haliassos and Michaelides (2003).
} 
Table 5: Probability of Holding Stocks or Stock Mutual Funds (All Ages); TNS 2007

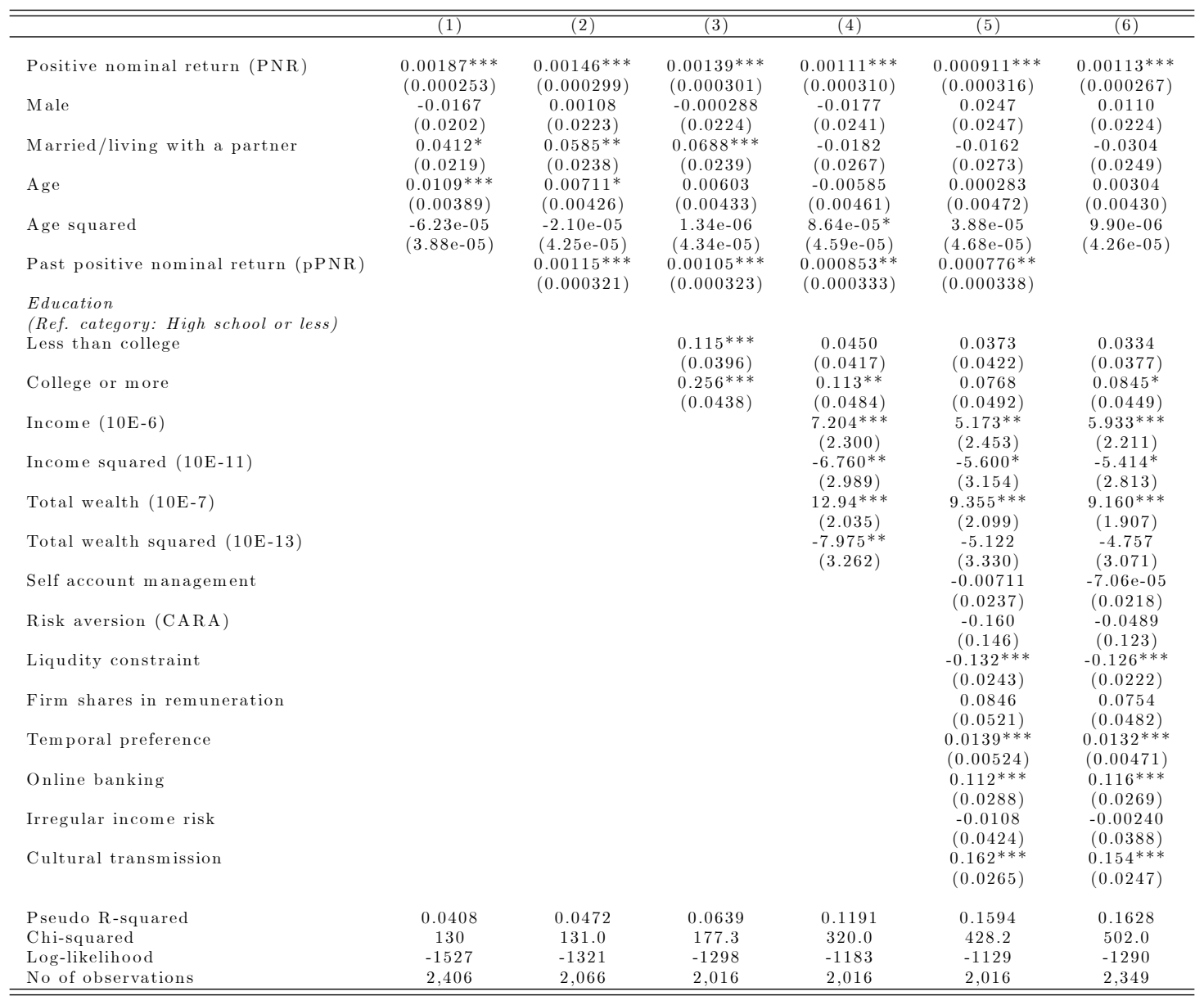

Note: (i) Standard errors are in parentheses. (ii) ${ }^{* * *} \mathrm{p}<0.01,{ }^{* *} \mathrm{p}<0.05,{ }^{*} \mathrm{p}<0.1$. 
theory. Individuals who have a long planning horizon (temporal preference) are 1.4 percent more likely to participate than those who are impatient, in line with empirical results by Donkers and van Soest (1999) for The Netherlands. More risk averse individuals also have a lower probability of participation, although the effect is not statistically significant. ${ }^{21}$ Overall, these effects are consistent with Van Nieuwerburgh and Veldkamp (2010), who model optimal information acquisition within the static two risky asset model in an expected utility framework. They find that at the extensive margin, temporal preference matters, since it determines the optimal amount of information, while risk aversion does not, because subjective stock market return expectations are formed conditional on respondents' individual information sets.

Constraints are very significant, in line with existing empirical results in the literature. Households who have been liquidity constrained or who think that they will be so in the future are less likely to participate (around 14\%). Deaton (1992) explains how the expectation of being liquidity constrained in the future leads prudent households to save more ('buffer stock'), which results in an overall reduction in stock ownership for those households whose preferences display both decreasing risk aversion (DARA) and prudence (DAP) -Elmendorf and Kimball (2000). ${ }^{22}$ Although income risk has a negative effect on stock ownership, in line with theoretical predictions (and simulations) that treat it as exogenous, the effect is not statistically significant. ${ }^{23}$

Finally, the age variables indicate that the probability of owning risky assets is lower for younger households, although it has a hump-shaped effect reaching its maximum at the age of 50. In Tables 6 and 7 below, we decompose the effect of expectations on stock market participation by age groups.

\subsection{Robustness}

In Table 6 we report the results of the estimation for respondents in the same age bracket (50-80) as those exploited by Dominitz and Manski (2007) from the HRS 2004. Two main messages emerge: (i) Dominitz and Manski's (2007) results are robust to the inclusion of previously identified covariates in the empirical literature of household finance, like transaction costs (proxied by wealth), liquidity constraints, income risk, access to the internet or preferences. (ii) Subjective stock market return expectations of the elderly determine their financial investment decisions at the extensive margin. However, information regarding past stock market performance does not because, as Figure 16 illustrates, they are overall very well informed.

In Table 7, we complete the life-cycle picture and report the estimation results only for the young

\footnotetext{
${ }^{21}$ The results are robust to an alternative measure of risk aversion: the coefficient of relative risk aversion for preferences in the constant relative risk aversion class (CRRA), advanced by Barsky et al. (1997) and available in the TNS 2007 survey wave. In addition, Kimball et al. (2008) show that the CRRA measure is robust to survey measurement error. The results are available from the authors upon request.

${ }^{22}$ See also Gollier (2001), who proves that the willigness to take risk is reduced in the presence of a liquidity constraint if absolute risk tolerance is increasing and convex in wealth.

${ }^{23}$ Tables 6 and 7 in the next subsection reveal that there is an age-composition effect of income risk on stock ownership: it has a negative and significant effect amongst the elderly (for whom it is either non-diversifiable or nonexistent), while a positive non-significant one amongst the young (for whom it is endogenous while non-diversifiable). See Arrondel and Calvo-Pardo (2011) for further details.
} 
Table 6: Probability of Holding Stocks or Stock Mutual Funds (50 $\leq$ Age $\leq 80)$; TNS 2007

\begin{tabular}{|c|c|c|c|c|c|c|}
\hline & $(1)$ & $(2)$ & $(3)$ & $(4)$ & $(5)$ & $(6)$ \\
\hline Positive nominal return (PNR) & $\begin{array}{r}0.00199 * * * \\
(0.000389)\end{array}$ & $\begin{array}{c}0.00179 * * * \\
(0.000457)\end{array}$ & $\begin{array}{c}0.00179 * * * \\
(0.000459)\end{array}$ & $\begin{array}{r}0.00144 * * * \\
(0.000481)\end{array}$ & $\begin{array}{r}0.00134 * * * \\
(0.000494)\end{array}$ & $\begin{array}{c}0.00135 * * * \\
(0.000419)\end{array}$ \\
\hline Male & $\begin{array}{l}0.0232 \\
(0.0327)\end{array}$ & $\begin{array}{l}0.0144 \\
(0.0363)\end{array}$ & $\begin{array}{l}-8.16 \mathrm{E}-05 \\
(0.0366)\end{array}$ & $\begin{array}{l}-0.0328 \\
(0.0404)\end{array}$ & $\begin{array}{l}-0.0406 \\
(0.0418)\end{array}$ & $\begin{array}{l}-0.0225 \\
(0.0372)\end{array}$ \\
\hline Married/living with a partner & $\begin{array}{c}0.0333 \\
(0.0356)\end{array}$ & $\begin{array}{c}0.0542 \\
(0.0393)\end{array}$ & $\begin{array}{l}0.0685^{*} \\
(0.0396)\end{array}$ & $\begin{array}{l}-0.0117 \\
(0.0441)\end{array}$ & $\begin{array}{l}-0.0109 \\
(0.0455)\end{array}$ & $\begin{array}{l}-0.0368 \\
(0.0408)\end{array}$ \\
\hline Age & $\begin{array}{c}0.0948^{* * *} \\
(0.0325)\end{array}$ & $\begin{array}{c}0.0758^{* *} \\
(0.0353)\end{array}$ & $\begin{array}{c}0.0840^{* * *} \\
(0.0356)\end{array}$ & $\begin{array}{c}0.0647^{*} \\
(0.037)\end{array}$ & $\begin{array}{l}0.0718^{*} \\
(0.0380)\end{array}$ & $\begin{array}{c}0.0917 * * * \\
(0.0348)\end{array}$ \\
\hline Age squared & $\begin{array}{c}-0.000724^{* * *} \\
(0.000257)\end{array}$ & $\begin{array}{c}-0.000564^{* *} \\
(0.000279)\end{array}$ & $\begin{array}{c}-0.000620^{* *} \\
(0.000282)\end{array}$ & $\begin{array}{l}-0.000472 \\
(0.000292)\end{array}$ & $\begin{array}{r}-0.000529^{*} \\
(0.000300)\end{array}$ & $\begin{array}{c}-0.000692^{* *} \\
(0.000274)\end{array}$ \\
\hline Past positive nominal return ( $\mathrm{pPNR}$ ) & & $\begin{array}{c}0.0005 \\
(0.000503)\end{array}$ & $\begin{array}{c}0.000507 \\
(0.000505)\end{array}$ & $\begin{array}{c}0.000204 \\
(0.000538)\end{array}$ & $\begin{array}{c}0.000322 \\
(0.000544)\end{array}$ & \\
\hline $\begin{array}{l}\text { Education } \\
\text { (Ref. category: High school or less) }\end{array}$ & & & & & & \\
\hline Less than college & & & $\begin{array}{c}0.135^{* * *} * \\
(0.0486)\end{array}$ & $\begin{array}{c}0.0799 \\
(0.0513)\end{array}$ & $\begin{array}{c}0.0746 \\
(0.0525)\end{array}$ & $\begin{array}{c}0.0617 \\
(0.0468)\end{array}$ \\
\hline College or more & & & $\begin{array}{c}0.204^{* * *} \\
(0.0548)\end{array}$ & $\begin{array}{c}0.0568 \\
(0.0645)\end{array}$ & $\begin{array}{c}0.0380 \\
(0.0673)\end{array}$ & $\begin{array}{c}0.0470 \\
(0.0616)\end{array}$ \\
\hline Income $(10 \mathrm{E}-6)$ & & & & $\begin{array}{l}8.739^{* *} \\
(3.905)\end{array}$ & $\begin{array}{c}5.472 \\
(4.149)\end{array}$ & $\begin{array}{l}5.932 \\
(3.808)\end{array}$ \\
\hline Income squared (10E-11) & & & & $\begin{array}{l}-8.942^{*} \\
(5.426)\end{array}$ & $\begin{array}{l}-6.386 \\
(5.678)\end{array}$ & $\begin{array}{l}-6.722 \\
(5.281)\end{array}$ \\
\hline Total wealth $(10 \mathrm{E}-7)$ & & & & $\begin{array}{c}14.62 * * * \\
(3.37)\end{array}$ & $\begin{array}{c}12.42 * * * \\
(3.486)\end{array}$ & $\begin{array}{c}12.17^{* * * *} \\
(3.126)\end{array}$ \\
\hline Total wealth squared (10E-13) & & & & $\begin{array}{c}-10.73^{* *} \\
(5.048)\end{array}$ & $\begin{array}{l}-9.659^{*} \\
(5.194)\end{array}$ & $\begin{array}{l}-9.009^{*} \\
(4.762)\end{array}$ \\
\hline Self account management & & & & & $\begin{array}{c}-0.0578 \\
(0.0388)\end{array}$ & $\begin{array}{l}-0.0396 \\
(0.0354)\end{array}$ \\
\hline Risk aversion (CARA) & & & & & $\begin{array}{c}-0.0319 \\
(0.209)\end{array}$ & $\begin{array}{l}0.0311 \\
(0.180)\end{array}$ \\
\hline Liquidity constraint & & & & & $\begin{array}{c}-0.147 * * * \\
(0.0415)\end{array}$ & $\begin{array}{c}-0.132 * * * \\
(0.0374)\end{array}$ \\
\hline Firm shares in remuneration & & & & & $\begin{array}{l}-0.0219 \\
(0.0988)\end{array}$ & $\begin{array}{c}0.0128 \\
(0.0957)\end{array}$ \\
\hline Temporal preference & & & & & $\begin{array}{l}0.0156^{*} \\
(0.00904)\end{array}$ & $\begin{array}{l}0.0156^{*} \\
(0.00802)\end{array}$ \\
\hline Online banking & & & & & $\begin{array}{c}0.178 * * * \\
(0.0514)\end{array}$ & $\begin{array}{l}0.181 * * * \\
(0.0486)\end{array}$ \\
\hline Irregular income risk & & & & & $\begin{array}{l}-0.154^{*} \\
(0.0837)\end{array}$ & $\begin{array}{l}-0.157^{* *} \\
(0.0741)\end{array}$ \\
\hline Cultural transmission & & & & & $\begin{array}{l}0.182 * * * \\
(0.0445)\end{array}$ & $\begin{array}{l}0.178^{* * *} * \\
(0.0416)\end{array}$ \\
\hline Pseudo R-squared & 0.0297 & 0.0306 & 0.042 & 0.0989 & 0.1438 & 0.1463 \\
\hline Chi-squared & 40.84 & 35.88 & 49.23 & 110.9 & 161.2 & 192.3 \\
\hline Log-likelihood & -666.9 & -568.1 & -561.4 & -505.1 & -480.0 & -561.0 \\
\hline No of Observations & 1,000 & 847 & 813 & 813 & 813 & 962 \\
\hline
\end{tabular}

Note: (i) Standard errors are in parentheses. (ii) ${ }^{* * *} \mathrm{p}<0.01,{ }^{* *} \mathrm{p}<0.05,{ }^{*} \mathrm{p}<0.1$ 
Table 7: Probability of Holding Stocks or Stock Mutual Funds (Age < 50); TNS 2007

\begin{tabular}{|c|c|c|c|c|c|c|}
\hline & $(1)$ & $(2)$ & $(3)$ & $(4)$ & $(5)$ & $(6)$ \\
\hline Positive nominal return (PNR) & $\begin{array}{r}0.00177^{* * *} * \\
(0.000331)\end{array}$ & $\begin{array}{c}0.00118^{* * *} \\
(0.000392)\end{array}$ & $\begin{array}{c}0.00106 * * * \\
(0.000393)\end{array}$ & $\begin{array}{c}0.000750^{*} \\
(0.000403)\end{array}$ & $\begin{array}{c}0.000486 \\
(0.000409)\end{array}$ & $\begin{array}{r}0.000855^{* *} \\
(0.000348)\end{array}$ \\
\hline Male & $\begin{array}{l}0.0174 \\
(0.0255)\end{array}$ & $\begin{array}{c}0.000113 \\
(0.0279)\end{array}$ & $\begin{array}{l}0.0115 \\
(0.0281)\end{array}$ & $\begin{array}{l}0.000977 \\
(0.0302)\end{array}$ & $\begin{array}{c}-0.00601 \\
(0.0308)\end{array}$ & $\begin{array}{l}0.00320 \\
(0.0280)\end{array}$ \\
\hline Married/living with a partner & $\begin{array}{c}0.0233 \\
(0.0287)\end{array}$ & $\begin{array}{l}0.0370 \\
(0.031)\end{array}$ & $\begin{array}{l}0.0491 \\
(0.031)\end{array}$ & $\begin{array}{l}-0.0379 \\
(0.0348)\end{array}$ & $\begin{array}{l}-0.0298 \\
(0.0355)\end{array}$ & $\begin{array}{l}-0.0361 \\
(0.0328)\end{array}$ \\
\hline Age & $\begin{array}{c}0.0400 * * * \\
(0.0134)\end{array}$ & $\begin{array}{c}0.0436 * * * \\
(0.0146)\end{array}$ & $\begin{array}{c}0.0335^{* *} \\
(0.015)\end{array}$ & $\begin{array}{c}2.45 \mathrm{E}-02 \\
(0.0158)\end{array}$ & $\begin{array}{l}0.0301 * \\
(0.0163)\end{array}$ & $\begin{array}{c}0.0230 \\
(0.0150)\end{array}$ \\
\hline Age squared & $\begin{array}{c}-0.000497^{* * *} \\
(0.000190)\end{array}$ & $\begin{array}{c}-0.000573^{* * *} \\
(0.000207)\end{array}$ & $\begin{array}{c}-0.000420^{* *} \\
(0.000212)\end{array}$ & $\begin{array}{r}-0.000371 * \\
(0.000223)\end{array}$ & $\begin{array}{r}-0.000407^{*} \\
(0.000230)\end{array}$ & $\begin{array}{l}-0.000291 \\
(0.000211)\end{array}$ \\
\hline Past positive nominal return (pPNR) & & $\begin{array}{c}0.00165^{* * *} \\
(0.000411)\end{array}$ & $\begin{array}{c}0.00143 * * * \\
(0.000414)\end{array}$ & $\begin{array}{c}0.00122^{* * *} * \\
(0.000423)\end{array}$ & $\begin{array}{c}0.00118^{* * *} * \\
(0.000428)\end{array}$ & \\
\hline $\begin{array}{l}\text { Education } \\
\text { (Ref. category: High school or less) }\end{array}$ & & & & & & \\
\hline Less than college & & & $\begin{array}{c}0.168^{*} \\
(0.0874)\end{array}$ & $\begin{array}{c}0.0892 \\
(0.0909)\end{array}$ & $\begin{array}{c}0.0433 \\
(0.0928)\end{array}$ & $\begin{array}{c}0.0720 \\
(0.0833)\end{array}$ \\
\hline College or more & & & $\begin{array}{c}0.346^{* * * *} \\
(0.0988)\end{array}$ & $\begin{array}{l}0.197^{*} \\
(0.103)\end{array}$ & $\begin{array}{c}0.116 \\
(0.103)\end{array}$ & $\begin{array}{c}0.159^{*} \\
(0.0964)\end{array}$ \\
\hline Income $(10 \mathrm{E}-6)$ & & & & $\begin{array}{l}5.721^{*} \\
(3.052)\end{array}$ & $\begin{array}{c}4.588 \\
(3.228)\end{array}$ & $\begin{array}{l}5.793^{* *} \\
(2.904)\end{array}$ \\
\hline Income squared (10E-11) & & & & $\begin{array}{l}-5.042 \\
(3.973)\end{array}$ & $\begin{array}{l}-5.139 \\
(4.127)\end{array}$ & $\begin{array}{l}-4.779 \\
(3.654)\end{array}$ \\
\hline Total wealth (10E-7) & & & & $\begin{array}{c}11.16 * * * \\
(2.556)\end{array}$ & $\begin{array}{c}7.002^{* * * *} \\
(2.641)\end{array}$ & $\begin{array}{c}7.383 * * * \\
(2.418)\end{array}$ \\
\hline Total wealth squared (10E-13) & & & & $\begin{array}{l}-4.845 \\
(4.472)\end{array}$ & $\begin{array}{l}-1.238 \\
(4.580)\end{array}$ & $\begin{array}{l}-2.129 \\
(4.203)\end{array}$ \\
\hline Self account management & & & & & $\begin{array}{c}0.0281 \\
(0.0297)\end{array}$ & $\begin{array}{c}0.0308 \\
(0.0274)\end{array}$ \\
\hline Risk aversion ( $\mathrm{CARA})$ & & & & & $\begin{array}{l}-0.232 \\
(0.215)\end{array}$ & $\begin{array}{c}-0.0421 \\
(0.178)\end{array}$ \\
\hline Liquidity constraint & & & & & $\begin{array}{c}-0.130 * * * \\
(0.0298)\end{array}$ & $\begin{array}{c}-0.124 * * * \\
(0.0275)\end{array}$ \\
\hline Firm shares in remuneration & & & & & $\begin{array}{c}0.119^{*} \\
(0.0612)\end{array}$ & $\begin{array}{l}0.0944^{*} \\
(0.0549)\end{array}$ \\
\hline Temporal preference & & & & & $\begin{array}{l}0.0140^{* *} \\
(0.00642)\end{array}$ & $\begin{array}{c}0.0113^{*} \\
(0.00581)\end{array}$ \\
\hline Online banking & & & & & $\begin{array}{c}0.0683^{* *} \\
(0.0330)\end{array}$ & $\begin{array}{c}0.0722^{* *} \\
(0.0306)\end{array}$ \\
\hline Irregular income risk & & & & & $\begin{array}{c}0.0406 \\
(0.0481)\end{array}$ & $\begin{array}{c}0.0542 \\
(0.0445)\end{array}$ \\
\hline Cultural transmission & & & & & $\begin{array}{l}0.146^{* * *} \\
(0.0319)\end{array}$ & $\begin{array}{l}0.137 * * * \\
(0.0296)\end{array}$ \\
\hline Pseudo R-squared & 0.0331 & 0.0422 & 0.657 & 0.1247 & 0.1693 & 0.1746 \\
\hline Chi-squared & 56.94 & 63.78 & 99.36 & 185.4 & 251.8 & 294.8 \\
\hline Log-likelihood & -830.8 & -724.3 & -706.5 & -650.8 & -617.6 & -697.0 \\
\hline No of Observations & 1,372 & 1,188 & 1,174 & 1,174 & 1,174 & 1,355 \\
\hline
\end{tabular}

Note: (i) Standard errors are in parentheses. (ii) ${ }^{* * *} \mathrm{p}<0.01,{ }^{* *} \mathrm{p}<0.05,{ }^{*} \mathrm{p}<0.1$

(18-49 age bracket). The main message conveyed is that although subjective expectations determine the decision to enter the stock market by the young unconditionally, once we condition on individual information, the effect of expectations becomes statistically insignificant. The results, together with Figure 16, lend support to King and Leape (1987) and Hurd's (2009) conjectures: what determines stock market participation amongst the young is their degree of awareness regarding the investment opportunities the stock market offers, proxied by the likelihood that the stock market has gone up over the last five years (pPNR). ${ }^{24}$

Table 8 reports the estimation results of subjective expectations on a narrower definition of stockholdings (direct stockholders only) which excludes investment in the stock market through mutual funds, by age groups (18-49, 50-80 and all ages). Since mutual funds are professionally managed, narrowing the definition we expect that respondents' decisions are more responsive to

\footnotetext{
${ }^{24}$ In unreported regressions, we find that this overall conclusion is robust to unobserved state dependence, measured by the number of stock market operations carried over the previous year. These results are omitted to save on space, but are available upon request.
} 
their expectations. For each age group, we examine the within effect that conditioning on information (column 2) has on the unconditional effect (column 1) of expected stock market performance on the decision to invest in shares of national and foreign firms. For all age groups, the main message remains although quantitatively the estimated coefficients are roughly similar. Importantly, comparison of the last two columns of the table lends support to Dominitz and Manski's (2011) conjecture about the importance of heterogeneity in the amount of public information when accounting for heterogeneity in subjective expectations: part of the effect of expectations on actions (all ages, column 1) comes from the effect of information on expectations (all ages, column 2).

Finally, Table 9 reports the estimation results by financial decision taker (Account Manager) and by respondent's information. For each group, we examine the effect of conditioning on information (column 2, within each group) on the unconditional effect (column 1 within each age group) of subjective expectations on the decision.to invest (directly and indirectly) in risky assets. Irrespective of who takes financial decisions, or of how informed respondents are, expectations determine financial decisions.

Two additional observations are worth making: Firstly, for those who do not take financial decisions by themselves but rather delegate completely or partiallly to professionals, the conditional effect (column 2, financial advisor or other) is quantitatively larger both within (column 1, financial advisor or other) and relative to those who take all financial decisions by themselves (column 2, selfaccount management). Secondly, even amongst the uninformed, the effect of expectations on stock market participation is quantitatively very important and statistically very significant (column 2, pPNR $<100$ ), in line with elementary portfolio choice theory predictions (Arrow, 1965; Merton, 1969). Compared to the informed (column $1, \mathrm{pPNR}=100$ ), expectations matter even more. ${ }^{25}$ We rationalize this last finding as follows: if information determines expectations, within the most homogeneous information group one would expect expectations to differ less, and hence to be less important empirically in accounting for differences in investment decisions. In the limit, perfectly informed individuals would all form rational expectations, so that different choices could not be explained by differences in expectations. Dominitz and Manski (2011) report evidence consistent with persistence in the modal type of revision of expectations with new public information. Hence, if the informed process information similarly, they will revise their expectations similarly, and there will be less cross-sectional variation in their expectations than there will be amongst the uninformed.

\section{Conclusion}

Elementary static (Arrow, 1965) and dynamic (Merton, 1969; Samuelson, 1969) models of portfolio choice put emphasis on the importance of individuals' expectations to explain stock market participation. However, it has been pervasive in the empirical literature on household portfolios

\footnotetext{
${ }^{25}$ This effect appears very robust to loosening the definition of "informed". For example, when classifying respondents as informed if "pPNR >50" (those who gave more than a 50-50 percent chance of the stock market index going up over the last 5 years), and uninformed otherwise, the marginal effect of expectations on decisions for the informed was 0.0021 , whereas for the uninformed was 0.0057 .
} 
Table 8: Probability of Holding Stocks (Only); TNS 2007

\begin{tabular}{|c|c|c|c|c|c|c|}
\hline & \multicolumn{2}{|c|}{ Age $<50$} & \multicolumn{2}{|c|}{$50 \leq$ Age $\leq 80$} & \multicolumn{2}{|c|}{ All ages } \\
\hline & $(1)$ & $(2)$ & (1) & $(2)$ & $(1)$ & $(2)$ \\
\hline Positive nominal return (PNR) & $\begin{array}{c}0.000658^{* *} \\
(0.000261)\end{array}$ & $\begin{array}{c}0.000305 \\
(0.000307)\end{array}$ & $\begin{array}{c}0.000962^{* * * *} \\
(0.000347)\end{array}$ & $\begin{array}{c}0.000656 \\
(0.000415)\end{array}$ & $\begin{array}{c}0.000829 * * * \\
(0.000208)\end{array}$ & $\begin{array}{c}0.000525^{* *} \\
(0.000246)\end{array}$ \\
\hline Male & $\begin{array}{c}-0.001852 \\
(0.0208)\end{array}$ & $\begin{array}{c}-0.00843 \\
(0.0230)\end{array}$ & $\begin{array}{l}0.00722 \\
(0.0309)\end{array}$ & $\begin{array}{c}0.000795 \\
(0.0355)\end{array}$ & $\begin{array}{l}0.00146 \\
(0.0173)\end{array}$ & $\begin{array}{c}-0.00338 \\
(0.0194)\end{array}$ \\
\hline Married/living with a partner & $\begin{array}{l}-0.0109 \\
(0.0244)\end{array}$ & $\begin{array}{l}-0.0147 \\
(0.0269)\end{array}$ & $\begin{array}{l}-0.0136 \\
(0.0342)\end{array}$ & $\begin{array}{r}-0.00595 \\
(0.0388)\end{array}$ & $\begin{array}{l}-0.0131 \\
(0.0196)\end{array}$ & $\begin{array}{l}-0.0116 \\
(0.0217)\end{array}$ \\
\hline Age & $\begin{array}{r}-0.00802 \\
(0.0110)\end{array}$ & $\begin{array}{c}-0.00479 \\
(0.0122)\end{array}$ & $\begin{array}{c}0.0177 \\
(0.0286)\end{array}$ & $\begin{array}{l}0.00344 \\
(0.0319)\end{array}$ & $\begin{array}{l}0.000878 \\
(0.00337)\end{array}$ & $\begin{array}{r}-0.000246 \\
(0.00374)\end{array}$ \\
\hline Age squared & $\begin{array}{c}0.000116 \\
(0.000155)\end{array}$ & $\begin{array}{c}6.08 \mathrm{e}-05 \\
(0.000171)\end{array}$ & $\begin{array}{l}-0.000131 \\
(0.000225)\end{array}$ & $\begin{array}{l}-1.81 \mathrm{e}-05 \\
(0.000252)\end{array}$ & $\begin{array}{l}1.27 \mathrm{e}-05 \\
(3.32 \mathrm{e}-05)\end{array}$ & $\begin{array}{l}2.42 \mathrm{e}-05 \\
(3.67 \mathrm{e}-05)\end{array}$ \\
\hline Past positive nominal return (pPNR) & & $\begin{array}{c}0.00105^{* * *} \\
(0.000328)\end{array}$ & & $\begin{array}{c}0.000507 \\
(0.000461)\end{array}$ & & $\begin{array}{c}0.000799^{* * *} \\
(0.000268)\end{array}$ \\
\hline $\begin{array}{l}\text { Education } \\
\text { (Ref. category: High school or less) }\end{array}$ & & & & & & \\
\hline Less than college & $\begin{array}{c}0.150^{*} \\
(0.0780)\end{array}$ & $\begin{array}{c}0.146^{*} \\
(0.0880)\end{array}$ & $\begin{array}{c}0.0368 \\
(0.0408)\end{array}$ & $\begin{array}{c}0.0408 \\
(0.0468)\end{array}$ & $\begin{array}{c}0.0313 \\
(0.0305)\end{array}$ & $\begin{array}{c}0.0349 \\
(0.0346)\end{array}$ \\
\hline College or more & $\begin{array}{c}0.221 \\
(0.135)\end{array}$ & $\begin{array}{c}0.200 \\
(0.139)\end{array}$ & $\begin{array}{c}0.0393 \\
(0.0539)\end{array}$ & $\begin{array}{c}0.0447 \\
(0.0609)\end{array}$ & $\begin{array}{c}0.0445 \\
(0.0375)\end{array}$ & $\begin{array}{c}0.0453 \\
(0.0418)\end{array}$ \\
\hline Income $(10 \mathrm{E}-6)$ & $\begin{array}{c}3.546^{*} \\
(2.096)\end{array}$ & $\begin{array}{c}2.988 \\
(2.352)\end{array}$ & $\begin{array}{l}5.891^{*} \\
(3.287)\end{array}$ & $\begin{array}{l}6.107^{*} \\
(3.596)\end{array}$ & $\begin{array}{c}4.062^{* *} \\
(1.658)\end{array}$ & $\begin{array}{c}3.932^{* *} \\
(1.861)\end{array}$ \\
\hline Income squared (10E-11) & $\begin{array}{l}-1.077 \\
(2.553)\end{array}$ & $\begin{array}{l}-1.454 \\
(2.910)\end{array}$ & $\begin{array}{l}-6.512 \\
(4.540)\end{array}$ & $\begin{array}{l}-6.691 \\
(4.834)\end{array}$ & $\begin{array}{l}-2.674 \\
(2.010)\end{array}$ & $\begin{array}{l}-3.125 \\
(2.282)\end{array}$ \\
\hline Total wealth (10E-7) & $\begin{array}{c}8.305^{* * *} \\
(1.713)\end{array}$ & $\begin{array}{c}7.349^{* * *} \\
(1.891)\end{array}$ & $\begin{array}{c}9.623^{* * *} \\
(2.572)\end{array}$ & $\begin{array}{c}10.69^{* * *} * \\
(2.961)\end{array}$ & $\begin{array}{c}8.517^{* * *} \\
(1.443)\end{array}$ & $\begin{array}{c}8.393^{* * *} \\
(1.616)\end{array}$ \\
\hline Total wealth squared (10E-13) & $\begin{array}{c}-9.175^{* * *} \\
(2.739)\end{array}$ & $\begin{array}{c}-6.987^{* *} * \\
(3.028)\end{array}$ & $\begin{array}{c}-8.716^{* *} \\
(3.788)\end{array}$ & $\begin{array}{c}-10.06^{* *} \\
(4.280)\end{array}$ & $\begin{array}{c}-8.128^{* * *} \\
(2.196)\end{array}$ & $\begin{array}{c}-7.541^{* * *} \\
(2.430)\end{array}$ \\
\hline Self account management & $\begin{array}{c}0.0139 \\
(0.0202)\end{array}$ & $\begin{array}{c}0.00338 \\
(0.0221)\end{array}$ & $\begin{array}{c}0.0373 \\
(0.0294)\end{array}$ & $\begin{array}{c}0.0329 \\
(0.0330)\end{array}$ & $\begin{array}{c}0.0223 \\
(0.0169)\end{array}$ & $\begin{array}{c}0.0159 \\
(0.0187)\end{array}$ \\
\hline Risk aversion (CARA) & $\begin{array}{c}-0.0153 \\
(0.134)\end{array}$ & $\begin{array}{l}-0.207 \\
(0.157)\end{array}$ & $\begin{array}{l}0.0759 \\
(0.154)\end{array}$ & $\begin{array}{l}0.0527 \\
(0.184)\end{array}$ & $\begin{array}{c}0.0319 \\
(0.0982)\end{array}$ & $\begin{array}{c}-0.0535 \\
(0.115)\end{array}$ \\
\hline Liquidity constraint & $\begin{array}{c}-0.0600^{* * * *} \\
(0.0211)\end{array}$ & $\begin{array}{c}-0.0582^{* *} \\
(0.0230)\end{array}$ & $\begin{array}{c}-0.0954^{* * *} \\
(0.0304)\end{array}$ & $\begin{array}{c}-0.111^{* * *} \\
(0.0344)\end{array}$ & $\begin{array}{c}-0.0784^{* * *} \\
(0.0174)\end{array}$ & $\begin{array}{c}-0.0817^{* * *} * \\
(0.0194)\end{array}$ \\
\hline Firm shares in remuneration & $\begin{array}{c}0.0341 \\
(0.0405)\end{array}$ & $\begin{array}{c}0.0398 \\
(0.0452)\end{array}$ & $\begin{array}{c}-0.0111 \\
(0.0744)\end{array}$ & $\begin{array}{c}-0.0196 \\
(0.0798)\end{array}$ & $\begin{array}{c}0.0285 \\
(0.0375)\end{array}$ & $\begin{array}{c}0.0339 \\
(0.0416)\end{array}$ \\
\hline Temporal preference & $\begin{array}{c}0.00165 \\
(0.00438)\end{array}$ & $\begin{array}{c}0.00257 \\
(0.00486)\end{array}$ & $\begin{array}{c}0.0107 \\
(0.00692)\end{array}$ & $\begin{array}{c}0.0116 \\
(0.00812)\end{array}$ & $\begin{array}{c}0.00552 \\
(0.00378)\end{array}$ & $\begin{array}{c}0.00585 \\
(0.00428)\end{array}$ \\
\hline Online banking & $\begin{array}{c}0.0908^{* * *} \\
(0.0243)\end{array}$ & $\begin{array}{c}0.0919 * * * \\
(0.0262)\end{array}$ & $\begin{array}{c}0.238^{* * *} \\
(0.0462)\end{array}$ & $\begin{array}{c}0.254^{* * *} \\
(0.0497)\end{array}$ & $\begin{array}{c}0.142^{* * *} \\
(0.0230)\end{array}$ & $\begin{array}{c}0.147 * * * \\
(0.0249)\end{array}$ \\
\hline Irregular income risk & $\begin{array}{c}0.0234 \\
(0.0343)\end{array}$ & $\begin{array}{c}0.0119 \\
(0.0366)\end{array}$ & $\begin{array}{c}-0.00830 \\
(0.0693)\end{array}$ & $\begin{array}{c}-0.00461 \\
(0.0792)\end{array}$ & $\begin{array}{c}0.0226 \\
(0.0327)\end{array}$ & $\begin{array}{c}0.0179 \\
(0.0360)\end{array}$ \\
\hline Cultural transmission & $\begin{array}{c}0.104^{* * *} \\
(0.0232)\end{array}$ & $\begin{array}{c}0.112^{* * *} \\
(0.0250)\end{array}$ & $\begin{array}{c}0.132^{* * * *} \\
(0.0371)\end{array}$ & $\begin{array}{c}0.140^{* * *} \\
(0.0407)\end{array}$ & $\begin{array}{c}0.115^{* * *} \\
(0.0203)\end{array}$ & $\begin{array}{c}0.123^{* * *} \\
(0.0221)\end{array}$ \\
\hline Pseudo R-squared & 0.1765 & 0.1742 & 0.1649 & 0.1671 & 0.1705 & 0.1698 \\
\hline Chi-squared & 230.3 & 200.3 & 180.7 & 159.9 & 418.3 & 366.9 \\
\hline Log-likelihood & -537.2 & -474.9 & -457.6 & -398.6 & -1017 & -896.8 \\
\hline No of Observations & 1,355 & 1,174 & 962 & 813 & 2,349 & 2,016 \\
\hline
\end{tabular}

Note: (i) Standard errors are in parentheses. (ii) ${ }^{* * *} \mathrm{p}<0.01,{ }^{*} \mathrm{p}<0.05,{ }^{*} \mathrm{p}<0.1$ 
Table 9: Probability of Holding Stocks or Stock Mutual Funds; by Account Manager and Information; TNS 2007

\begin{tabular}{|c|c|c|c|c|c|c|}
\hline & \multicolumn{2}{|c|}{ S Self account management } & \multicolumn{2}{|c|}{ Financial advisor or other } & \multirow{2}{*}{$\begin{array}{c}\mathrm{pPNR}=100 \\
(1)\end{array}$} & \multirow{2}{*}{$\begin{array}{c}\mathrm{pPNR}<100 \\
(2) \\
\end{array}$} \\
\hline & $(1)$ & $(2)$ & $(1)$ & $(2)$ & & \\
\hline Positive nominal return (PNR) & $\begin{array}{r}0.00116^{* * *} \\
(0.000436)\end{array}$ & $\begin{array}{c}0.000784 \\
(0.000498)\end{array}$ & $\begin{array}{r}0.00138^{* * *} \\
(0.000474)\end{array}$ & $\begin{array}{r}0.00145 * * * \\
(0.000546)\end{array}$ & $\begin{array}{c}0.000620 \\
(0.000429)\end{array}$ & $\begin{array}{c}0.00114^{* * *} \\
(0.000432)\end{array}$ \\
\hline Male & $\begin{array}{l}0.103^{* * *} \\
(0.0367)\end{array}$ & $\begin{array}{l}0.0905^{* *} \\
(0.0394)\end{array}$ & $\begin{array}{c}-0.103^{* * *} \\
(0.0385)\end{array}$ & $\begin{array}{c}-0.110^{* * *} \\
(0.0417)\end{array}$ & $\begin{array}{l}0.0277 \\
(0.0391)\end{array}$ & $\begin{array}{c}-0.0717^{* *} \\
(0.0305)\end{array}$ \\
\hline Married/living with a partner & $\begin{array}{l}-0.0436 \\
(0.0409)\end{array}$ & $\begin{array}{l}-0.0274 \\
(0.0435)\end{array}$ & $\begin{array}{l}-0.0479 \\
(0.0433)\end{array}$ & $\begin{array}{l}-0.0316 \\
(0.0466)\end{array}$ & $\begin{array}{c}-0.0947^{* *} \\
(0.0433)\end{array}$ & $\begin{array}{c}0.0384 \\
(0.0330)\end{array}$ \\
\hline Age & $\begin{array}{c}0.00331 \\
(0.00719)\end{array}$ & $\begin{array}{l}0.00155 \\
(0.00770)\end{array}$ & $\begin{array}{c}0.0111 \\
(0.00760)\end{array}$ & $\begin{array}{c}0.00952 \\
(0.00806)\end{array}$ & $\begin{array}{l}-0.00577 \\
(0.00755)\end{array}$ & $\begin{array}{l}0.00246 \\
(0.00591)\end{array}$ \\
\hline Age squared & $\begin{array}{l}-6.36 \mathrm{e}-06 \\
(7.11 \mathrm{e}-05)\end{array}$ & $\begin{array}{l}1.08 \mathrm{e}-05 \\
(7.62 \mathrm{e}-05)\end{array}$ & $\begin{array}{l}-5.34 \mathrm{e}-05 \\
(7.46 \mathrm{e}-05)\end{array}$ & $\begin{array}{l}-3.73 \mathrm{e}-05 \\
(7.89 \mathrm{e}-05)\end{array}$ & $\begin{array}{l}7.84 \mathrm{e}-05 \\
(7.33 \mathrm{e}-05)\end{array}$ & $\begin{array}{l}2.49 \mathrm{e}-05 \\
(5.94 \mathrm{e}-05)\end{array}$ \\
\hline Past positive nominal return (pPNR) & & $\begin{array}{l}0.000879 \\
(0.000541)\end{array}$ & & $\begin{array}{c}0.000350 \\
(0.000565)\end{array}$ & & \\
\hline $\begin{array}{l}\text { Education } \\
\text { (Ref. category: High school or less) }\end{array}$ & & & & & & \\
\hline Less than college & $\begin{array}{c}0.0440 \\
(0.0702)\end{array}$ & $\begin{array}{c}0.0722 \\
(0.0762)\end{array}$ & $\begin{array}{c}0.00674 \\
(0.0633)\end{array}$ & $\begin{array}{c}0.00552 \\
(0.0690)\end{array}$ & $\begin{array}{c}0.0118 \\
(0.0665)\end{array}$ & $\begin{array}{c}0.0436 \\
(0.0529)\end{array}$ \\
\hline College or more & $\begin{array}{c}0.0940 \\
(0.0786)\end{array}$ & $\begin{array}{c}0.128 \\
(0.0846)\end{array}$ & $\begin{array}{c}0.125^{*} \\
(0.0729)\end{array}$ & $\begin{array}{c}0.0986 \\
(0.0787)\end{array}$ & $\begin{array}{r}-0.00146 \\
(0.0746)\end{array}$ & $\begin{array}{c}0.123^{*} \\
(0.0657)\end{array}$ \\
\hline Income $(10 \mathrm{E}-6)$ & $\begin{array}{l}7.285^{*} \\
(3.882)\end{array}$ & $\begin{array}{c}5.777 \\
(4.147)\end{array}$ & $\begin{array}{c}5.718 \\
(3.849)\end{array}$ & $\begin{array}{c}6.968 \\
(4.633)\end{array}$ & $\begin{array}{l}6.045^{*} \\
(3.541)\end{array}$ & $\begin{array}{c}6.418 \\
(4.372)\end{array}$ \\
\hline Income squared (10E-11) & $\begin{array}{l}-5.426 \\
(5.347)\end{array}$ & $\begin{array}{l}-4.842 \\
(5.607)\end{array}$ & $\begin{array}{l}-7.219 \\
(4.942)\end{array}$ & $\begin{array}{l}-10.18 \\
(6.503)\end{array}$ & $\begin{array}{l}-6.004 \\
(4.073)\end{array}$ & $\begin{array}{l}-10.24 \\
(7.737)\end{array}$ \\
\hline Total wealth (10E-7) & $\begin{array}{c}9.519 * * * \\
(3.191)\end{array}$ & $\begin{array}{c}8.867 * * * \\
(3.418)\end{array}$ & $\begin{array}{c}8.784^{* * *} \\
(3.265)\end{array}$ & $\begin{array}{c}8.393^{* *} \\
(3.517)\end{array}$ & $\begin{array}{c}11.34^{* * *} * \\
(3.307)\end{array}$ & $\begin{array}{c}8.004^{* * *} \\
(2.620)\end{array}$ \\
\hline Total wealth squared (10E-13) & $\begin{array}{l}-4.581 \\
(5.042)\end{array}$ & $\begin{array}{l}-3.266 \\
(5.320)\end{array}$ & $\begin{array}{l}-5.751 \\
(5.252)\end{array}$ & $\begin{array}{l}-5.987 \\
(5.651)\end{array}$ & $\begin{array}{l}-5.994 \\
(5.295)\end{array}$ & $\begin{array}{l}-4.896 \\
(4.134)\end{array}$ \\
\hline Risk aversion (CARA) & $\begin{array}{c}-0.0125 \\
(0.233)\end{array}$ & $\begin{array}{l}-0.114 \\
(0.259)\end{array}$ & $\begin{array}{l}-0.369 \\
(0.241)\end{array}$ & $\begin{array}{c}-0.474^{*} \\
(0.280)\end{array}$ & $\begin{array}{c}-0.430^{*} \\
(0.238)\end{array}$ & $\begin{array}{r}-0.0240 \\
(0.181)\end{array}$ \\
\hline Liquidity constraint & $\begin{array}{c}-0.0698^{*} \\
(0.0382)\end{array}$ & $\begin{array}{c}-0.0886^{* *} \\
(0.0410)\end{array}$ & $\begin{array}{c}-0.130^{* * *} \\
(0.0390)\end{array}$ & $\begin{array}{c}-0.131^{* * *} \\
(0.0418)\end{array}$ & $\begin{array}{c}-0.139 * * * \\
(0.0395)\end{array}$ & $\begin{array}{c}-0.124^{* * *} \\
(0.0299)\end{array}$ \\
\hline Firm shares in remuneration & $\begin{array}{c}0.0869 \\
(0.0731)\end{array}$ & $\begin{array}{c}0.0758 \\
(0.0778)\end{array}$ & $\begin{array}{c}0.0356 \\
(0.0779)\end{array}$ & $\begin{array}{c}0.0495 \\
(0.0812)\end{array}$ & $\begin{array}{c}0.0723 \\
(0.0736)\end{array}$ & $\begin{array}{c}0.0748 \\
(0.0722)\end{array}$ \\
\hline Temporal preference & $\begin{array}{c}0.0100 \\
(0.00824)\end{array}$ & $\begin{array}{c}0.0105 \\
(0.00884)\end{array}$ & $\begin{array}{c}0.0133 \\
(0.00826)\end{array}$ & $\begin{array}{c}0.0143 \\
(0.00896)\end{array}$ & $\begin{array}{c}0.0225^{* * *} \\
(0.00831)\end{array}$ & $\begin{array}{c}0.00861 \\
(0.00650)\end{array}$ \\
\hline Online banking & $\begin{array}{c}0.121^{* * *} \\
(0.0388)\end{array}$ & $\begin{array}{c}0.118^{* * *} \\
(0.0408)\end{array}$ & $\begin{array}{c}0.0273 \\
(0.0458)\end{array}$ & $\begin{array}{c}0.0302 \\
(0.0485)\end{array}$ & $\begin{array}{l}0.105^{* *} \\
(0.0423)\end{array}$ & $\begin{array}{c}0.106^{* * *} \\
(0.0388)\end{array}$ \\
\hline Irregular income risk & $\begin{array}{c}0.105 \\
(0.0674)\end{array}$ & $\begin{array}{c}0.117 \\
(0.0725)\end{array}$ & $\begin{array}{l}-0.120^{*} \\
(0.0667)\end{array}$ & $\begin{array}{l}-0.133^{*} \\
(0.0709)\end{array}$ & $\begin{array}{r}-0.00265 \\
(0.0699)\end{array}$ & $\begin{array}{l}-0.0110 \\
(0.0512)\end{array}$ \\
\hline Cultural transmission & $\begin{array}{c}0.109 * * * \\
(0.0384)\end{array}$ & $\begin{array}{l}0.105^{* *} \\
(0.0409)\end{array}$ & $\begin{array}{c}0.173^{* * *} \\
(0.0397)\end{array}$ & $\begin{array}{c}0.199 * * * \\
(0.0413)\end{array}$ & $\begin{array}{c}0.183^{* * *} * \\
(0.0395)\end{array}$ & $\begin{array}{c}0.141^{* * *} \\
(0.0348)\end{array}$ \\
\hline Self account management & & & & & $\begin{array}{c}0.0202 \\
(0.0374)\end{array}$ & $\begin{array}{l}-0.0299 \\
(0.0294)\end{array}$ \\
\hline Pseudo R-squared & 0.1475 & 0.1456 & 0.1482 & 0.1503 & 0.1498 & 0.1588 \\
\hline Chi-squared & 188.2 & 166.0 & 178.1 & 158.1 & 184.5 & 222.6 \\
\hline Log-likelihood & -543.9 & -487.0 & -511.6 & -447.0 & -523.8 & -589.7 \\
\hline No of Observations & 945 & 839 & 867 & 761 & 891 & 1,124 \\
\hline
\end{tabular}

Note: (i) Standard errors are in parentheses. (ii) ${ }^{* * *} \mathrm{p}<0.01,{ }^{*} \mathrm{p}<0.05,{ }^{*} \mathrm{p}<0.1$ 
to adopt the rational expectations assumption, thus neglecting a potential source of heterogeneity that, in addition to heterogeneity in preferences, endowments and constraints, could help reconcile economic theory predictions with empirically observed low participation rates.

In line with some recent efforts in the literature (Dominitz and Manski, 2007; Hurd et al., 2011; Kézdi and Willis, 2009; Miniaci and Pastorello, 2010), here we have collected novel data on households' expectations and, importantly, on households' information sets (TNS 2007). To validate our novel data set, and for comparison purposes, we have adopted Dominitz and Manski's (2007) methodology. Our results confirm that the novel effect of expectations on the decision to participate in the stock market first identified by them, is robust to the inclusion of measures of information, risk and time preference, endowments, constraints and management, for a representative sample by age and wealth. Most of the included factors had been previously identified in the literature as important determinants of age-portfolio profiles at the extensive margin. Similar conclusions ground the works by Hurd et al. (2011), Kézdi and Willis (2009) or Miniaci and Pastorello (2010).

Taking advantage of our novel information measure, we are able to (i) confirm King and Leape (1987) - Hurd's (2009) conjecture, on the importance of being aware of the investment opportunities offered by the stock market, specially to account for low participation rates of the young; (ii) confirm the basic principle of elementary portfolio choice models, since even amongst the uninformed, subjective stock market expectations determine their decision to participate; (iii) confirm the effect of social interactions, professional advice, past own experience and specialised media access, as relevant sources of information at the individual level, thereby contributing to the literature on financial literacy and trust. However, (iv) although males appear better informed and are also more likely to take financial decisions themselves instead of delegating, conditioning on gender, optimists appear less well informed, at odds with a behavioural overconfidence bias interpretation (Guiso and Jappelli, 2006), but in line with an inertia amongst the general population (Bilias et al., 2010). As well, (v) poor or constrained households, for whom stock market information is useless, appear less well informed in line with rational inattention models (Sims, 2003).

However many questions remain, that would require further data collection and analysis. ${ }^{26}$ Perhaps the most important one is that much observed heterogeneity remains unexplained at the extensive margin. In light of our results, and the recent crisis (Hall, 2010), attempts to understand Dominitz and Manski's (2011) conjecture about heterogeneity processing in public information feeding heterogeneity in subjective expectations, is likely to be the most promising and challenging one.

\footnotetext{
${ }^{26}$ Data collection is crucial if one aims at understanding the macroeconomic implications and derive policy reccomendations using a realistically calibrated dynamic macroeconomic model (see for example Alan, 2010).
} 


\section{References}

Alan, S. (2010), 'Do Disaster Expectations Explain Household Portfolios?', Centre for Financial Analysis and Policy WP No. 34, Univeristy of Cambridge.

Arrondel, L., and H. Calvo-Pardo (2011), 'Temperance in French Household Portfolios?', mimeo.

Arrondel, L., Calvo-Pardo, H., and X. Oliver (2011), 'Subjective Stock Market Expectations, Information and the Demand for Risky Assets', mimeo.

Arrow, K. J. (1965). Aspects of the Theory of Risk Bearing, Yrjo Jahnsson Lectures, The Academic Book Store, Helsinki.

Arthur, W. B. (2006), 'Out-of-Equilibrium Economics and Agent-Based Modeling', in K. Judd and L. Tesfatsion, eds, Handbook of Computational Economics, Vol. 2: Agent-Based Com-putational Economics, Elsevier/North-Holland Publishers.

Barsky, R. B., Juster, T. F., Kimball, M. S. and Shapiro, M. D. (1997), 'Preference Parameters and Behavioral Heterogeneity: an Experimental Approach in the Health and Retirement Study,' Quarterly Journal of Economics, CXII: 537-580.

Bilias, Y., D. Georgarakos and M. Haliassos (2010), 'Portfolio Inertia and Stock Market Fluctuations', Journal of Money, Credit and Banking, 42(4): 715-742.

Brandt, M. W. (2008), 'Portfolio Choice Problems,' in Y. Ait-Sahalia and L.P. Hansen, eds., Handbook of Financial Econometrics, Elsevier Science: Amsterdam.

Bruine de Bruin, W., B. Fischhoff, S. Millstein and B. Halpbern-Felscher (2000), 'Verbal and numerical expressions of probability: It's a Fifty-Fifty Chance,' Organizational Behavior and Human Decision Processes, 81(1): 115-131.

Cabrales, A. and P. Gottardi (2011), 'Markets for Information: On Inefficient Firewalls and Efficient Monopolies,' mimeo.

Campbell, J. Y. (2006), 'Household Finance,' The Journal of Finance, 61: 1553-1604.

Campbell, J. Y., Lo, A. W., and A. C. MacKinlay (1997), The Econometrics of Financial Markets, Princeton University Press, Princeton, New Jersey.

Deaton, A. (1992), Understanding Consumption, Oxford: Clarendon Press.

Dominitz, J. and C. Manski (1997), 'Using Expectations Data to Study Income Expectations,' Journal of the American Statistical Association, 92: 855-67.

Dominitz, J. and C. Manski (2007), 'Expected Equity Returns and Portfolio Choice: Evidence from the Health and Retirement Study,' Journal of the European Economic Association 5: 369-79. 
Dominitz, J. and C. Manski (2011), 'Measuring and Interpreting Expectations of Equity Returns,' Journal of Applied Econometrics, 26: 352-370.

Donkers, B. and A. van Soest (1999), 'Subjective measures of household preferences and financial decisions,' Journal of Economic Psychology 20: 613-642

Dow, J., and S. R. da Costa Werlang (1992), 'Uncertainty Aversion, Risk Aversion, and the Optimal Choice of Portfolio,' Econometrica, 60: 197-204.

Elmendorf, Douglas W. and Miles S. Kimball (2000), 'Taxation of labor income and the demand for risky assets,' International Economic Review, 41: 801-832.

Evans, G. W., and S. Honkapohja (2001), Learning and Expectations in Macroeconomics, Princeton U. Press, Princeton, NJ.

Gollier, C. (2001), The Economics of Risk and Time, Cambridge: MIT Press.

Gourieroux, C., Monfort, A., and Trognon, A. (1987). 'Simulated Residuals,' Journal of Econometrics, 34: 201-252.

Gomes, F. and A. Michaelides (2005), 'Optimal Life-cycle Asset Allocation: Understanding the Empirical Evidence,' The Journal of Finance 60(2): 869-904.

Guesnerie, R. (1992), "An Exploration of the Eductive Justifications of the Rational Expectations Hypothesis", American Economic Review 82 :1254-1278.

Guiso, L. and T. Jappelli (2005), 'Awareness and Stock Market Participation,' Review of Finance, 9: 537567.

Guiso, L. and T. Jappelli (2007), 'Information Acquisition and Portfolio Performance,' EUI WP ECO $2007 / 45$.

Guiso, L. and M. Paiella (2008), 'Risk Aversion, Wealth and Background Risk,' Journal of the European Economic Association, 6: 1109-1150.

Guiso, L., T. Jappelli and D. Terlizzese (1996), 'Income risk, borrowing constraints and portfolio choice,' American Economic Review, 86: 158-172.

Guiso, L., M. Haliassos and T. Jappelli (2002), Household Portfolios, Cambridge: MIT Press.

Guiso, L., Sapienza, P., and L. Zingales (2008), 'Trusting the stock market,' The Journal of Finance, 63: 2557-2600.

Haliassos, M. (2008), 'Household Portfolios,' in The New Palgrave Dictionary of Economics, Eds. Steven N. Durlauf and Lawrence E. Blume, Palgrave Macmillan, and in The New Palgrave Dictionary of Economics Online, Palgrave Macmillan. 
Haliassos, M. and C. Bertaut (1995), 'Why Do So Few Hold Stocks?,' Economic Journal, 105: 1110-29.

Hall, R. E. (2010), 'Why Does the Economy Fall to Pieces after a Financial Crisis?,' Journal of Economic Perspectives, 24(4): 3-20.

Heaton, J., and D. Lucas (2000), 'Asset pricing and portfolio choice: the importance of entrepreneurial risk', The Journal of Finance, 55: 1163-1198.

Hommes, C. (2011), 'The Heterogeneous Expectations Hypothesis: Some Evidence from the Lab', Journal of Economic Dynamics and Control, forthcoming.

Hong, H., Kubik, J.D., and J.C. Stein (2004), 'Social interaction and stock market participation,' The Journal of Finance, 59: 137-163.

Hurd, M. D. (2009), 'Subjective Probabilities in Household Surveys', Annual Review of Economics, 1: $543-62$.

Hurd, M. D., M. van Rooij and J. Winter (2011), 'Stock Market Expectations of Dutch Households', Journal of Applied Econometrics forthcoming.

Kézdi, G. and R. J. Willis (2009), 'Stock Market Expectations and Portfolio Choice of American Households,' mimeo.

Kimball, M. S., C. R. Sham and M. D. Shapiro (2008), 'Imputing Risk Tolerance from Survey Responses,' Journal of the American Statistical Association, 103 (483): 1028-38.

King, M.A., and J. I. Leape (1987), 'Asset accumulation, information and the life cycle,' NBER wp No. 2392.

King, M.A., and J. I. Leape (1998), 'Wealth and portfolio composition: Theory and Evidence,' Journal of Public Economics 69: 155-93.

Lusardi, A. (2008), 'Financial Literacy: An Essential Tool for Informed Consumer Choice?,' mimeo.

Manski, C. (2004), 'Measuring Expectations,' Econometrica, 72: 1329-76.

Merton, R. C. (1969), 'Lifetime Portfolio Selection under Uncertainty: The Continuous Time Case,' Review of Economics and Statistics, 51(3): 247-257.

Miniaci, R. and S. Pastorello (2010), 'Mean-Variance Econometric Analysis of Household Portfolios,' Journal of Applied Econometrics 25: 481-504

Paiella, M. (2001), 'Transaction Costs and Limited Stock Market Participation to Reconcile Asset Prices and Consumption Choices', IFS Working Paper.

Peress, J. (2004), 'Wealth, Information Acquisition and Portfolio Choice,' Review of Financial Studies 17(3): 879-914. 
Pesaran, M. H., and M. Weale (2006), 'Survey Expectations,' in G. Elliott, C.W.J. Granger and A. Timmermann, eds., Handbook of Economic Forecasting, North-Holland.

Poterba, J. M. (2002), 'Taxation and Portfolio Structure: Issues and Implications,' in L. Guiso, M. Haliassos and T. Jappelli Eds., Household Portfolios, Cambridge: MIT Press.

Sims, C. (2003), 'Implications of Rational Inattention', Journal of Monetary Economics 50(3): 665-90.

Samuelson, P. A. (1969), 'Lifetime Portfolio Selection by Dynamic Stochastic Programming,' Review of Economics and Statistics, 51(3): 239-246.

Stiglitz, J. E. (2011), 'Rethinking Macroeconomics: What Went Wrong and How to Fix it,' Journal of the European Economic Association, 9(4): 594-645.

Van Nieuwerburgh, S. and L. Veldkamp (2010), 'Information Acquisition and Under-Diversification,' Review of Economic Studies, 77(2): 779-805.

Vissing-Jorgensen, A. (2002), 'Towards and Explanation of Household Portfolio Choice Heterogeneity: Nonfinancial Income and Participation Cost Structures,' mimeo.

Vissing-Jorgensen, A. (2004), 'Perspectives on Behavioural Finance: Does Irrationality Disappear with Wealth? Evidence from Expectations and Actions,' in: M. Gertler and K. Rogoff eds., The NBER Macroeconomics Annual 2003, Cambridge: MIT Press.

Zhang, X.F. (2006), 'Information Uncertainty and Stock Market Returns,' The Journal of Finance, 61(1): 105-137. 


\section{Appendix}

\section{Variable Definitions}

\section{Endowments}

Total wealth: In the survey, the respondent is asked in which of the eight predefined available brackets is her household's situation. As we are interested in a continuous measure, we have used the method of simulated residuals (Gourieroux et al. 1987). We have regressed an ordered probit of the respondents' total wealth (bracket) on demographic and socio-economic household characteristics. Once we have the estimated total wealth, a normally distributed error is added. We then check if the value falls inside the bracket originally chosen by the individual. If not, another normal error is added and so on until we predict the true interval. Doing so allows us to overcome the non-response problem for some households. If there is a missing value, the predicted value plus a normal error is directly used. Total wealth is given in Euros.

Income: For the income of the household, the survey asks the respondent which of the 7 predefined available brackets better corresponds to her situation. We obtained a continuous measure in the same way we did for total wealth. Income refers to the individual's household annual income in Euros.

\section{Preferences}

Absolute risk aversion (CARA): The following question is asked to the respondent: 'If someone suggests that you make an investment, $\widetilde{S}_{i}$, whereby you have one chance out of two win 5000 euros and one chance out of two of losing the capital invested, how much (as a maximum) will you invest?' The question aims at eliciting the taste for risk from each respondent $i$, with preferences $u^{i}($.$) , from the$ following equality:

$$
u^{i}\left(w_{i}\right)=\frac{1}{2} u^{i}\left(w_{i}+5,000\right)+\frac{1}{2} u^{i}\left(w_{i}-Z_{i}\right) \equiv E u^{i}\left(w_{i}+\widetilde{S}_{i}\right)
$$

The coefficient of absolute risk aversion (CARA) can be then obtained from a second order Taylor expansion, as $A_{i}\left(w_{i}\right)=2\left(5000-Z_{i}\right) /\left(5000^{2}+Z_{i}^{2}\right)$, where $Z_{i}$ is the amount that the respondent declares to be willing to invest. Those who declare $Z_{i}<5000$ are risk-averse $Z_{i}=5000$, are riskneutral and $Z_{i}>5000$ are risk-lovers. The ourcome range for the coefficient of absolute risk aversion $A_{i}\left(w_{i}\right)$ is $[0,40] .3,343$ respondents answered the question, with a mean response of 39.11. In the TNS 2007, the histogram of responses is very skewed to the left. Further details regarding the measure of absolute risk aversion (CARA) can be found in Guiso and Paiella's (2008) work.

Relative risk aversion (CRRA): To obtain a measure of risk aversion, we asked individuals about their willingness to gamble on lifetime income according to the methodology of Barsky et al. (1997). The "game" resides in determining sequentially whether the interviewee would accept to give up his present income and to accept other contracts, in the form of lotteries: he has one chance in two to double his 
income, and one chance in two for it to be reduced by one third (contract A), by one half (contract $\mathrm{B})$, and by one fifth (contract C). More precisely, the question in the survey was:

* 'Suppose that you have a job which guarantees for life your household's current income R. Other companies offer you various contracts which have one chance out of two (50\%) to provide you with a higher income and one chance out of two $(50 \%)$ to provide you with a lower income.

* Are you prepared to accept Contract A which has 50\% chances to double your income R and $50 \%$ chances that your income will be reduced by one third?

* For those who answer YES : the Contract A is no longer available. You are offered Contract B instead which has $50 \%$ chances to double your income $\mathrm{R}$ and $50 \%$ chances that it will be reduced by one half. Are you prepared to accept?

* For those who answer NO : you have refused Contract A. You are offered Contract C. which has 50\% chances to double your income $\mathrm{R}$ and $50 \%$ chances that it will be reduced by $20 \%$. Are you prepared to accept?'

This allows us to obtain a range measure of relative risk aversion under the assumption that preferences are strictly risk averse and utility is of the CRRA type. The degree of relative risk aversion is less than 1 if the individual successively accepts contracts A and B; between 1 and 2 if he accepts A but refuses B; between 2 and 3.76 if he refuses $\mathrm{A}$ but accepts $\mathrm{C}$; and finally more than 3.76 if he refuses both $\mathrm{A}$ and $\mathrm{C}$.

Temporal preference: It is a numerical scale from 0 to 10 . The surveys asks the respondent about her attitude regarding life: 0 represents living the present (impatience) and 10 only caring about the future (extreme patience).

\section{Demographics}

Gender: is a dummy variable equal to 1 if the household head is a male, and is equal to 0 , if a female.

Marital status: Marital status is based on current legal marital status. Respondents who are married or/and living with a partner are coded as 1 , and 0 otherwise.

\section{Constraints}

Liquidity constrained: Respondents are asked if they ever had to struggle to pay their budget. It is a dummy variable that takes value 1 if the respondent answers the question in the categories 'very often' or 'often', and value 0 otherwise.

Online banking: It is a dummy variable that takes value 1 if the respondent uses the internet for managing her financial accounts, and 0 otherwise.

Importance of Money in Life: Respondents are asked about the relative importance of money in life. It is a quantitative variable on a discrete scale from 0 to 10. 
Income Risk: Question qa16 in the survey asks respondents about the regularity of household's income (wages, retirement income...), providing three categories: 'regular, certain'; 'irregular, random' and 'partly certain, partly random'. Income risk is defined as a dummy variable that takes value 1 if the respondent answers 'irregular, random', and zero otherwise.

\section{Delegation/Inertia}

Self portfolio management: The survey asks the respondent who takes household's financial decisions (stocks, SICAV/FCP bonds, life insurance contracts, saving accounts). Respondents who answer 'themselves' or 'them with their partners' are coded as 1 , and 0 otherwise (which includes sharing some decisions with a financial advisor, or the financial advisor taking all decisions on the households' behalf).

Firm shares in remuneration: It is a dummy variable that takes value 1 if the respondent receives shares of the firm he works in as part of her compensation package/remuneration, and 0 otherwise.

Frequency of recent trades: Respondents are asked about the number of stock market operations closed over the year prior to the date in which the survey was conducted (March 2006-March 2007). The answers are categorical: no operations, 1-2 operations, 3-5 operations, 6 or more operations.

Optimism: Respondents are inquired 'whether they esteem that they have been lucky in life'. It is a discrete variable, that takes value 1 if they answer 'yes', and 0 otherwise.

\section{Information}

Education: is a categorical variable, grouped into three broad categories: High school or less (primary and secondary), some college (technical degrees beyond high school but below college, including professional and vocational degrees) and college or more (BAs, BScs, MScs, MBAs, professional certifications, PhDs and postdoctoral students).

Sources of Information variables:

* Respondents are inquired, for each alternative source of information (Friends, family, financial advisors, general media and specialised media), about the relative frequency of consultation (often, sometimes or never). For each information source, a dummy variable is created which takes value 1 if the answer is 'often', and 0 otherwise.

* Respondents are inquired, for each alternative source of TV information (General information and economics emissions), about the relative frequency of consultation (very often, often, occasionally, sometimes or never). For each information source, a dummy variable is created which takes value 1 if the answer is 'often' or 'very often', and 0 otherwise.

Mother's education: The respondent is inquired about the educational attainment of her mother. Three categories are available: less than High school, completed High school and more than High school. The reference category is 'less than High school'. 
Father's education: The respondent is inquired about the educational attainment of her father. Three categories are available: less than High school, completed High school and more than High school. The reference category is 'less than High school'.

Family background: The respondent is inquired about her family background. Three categories are available: Middle class, low class and neither middle nor low class. The reference category is 'neither middle nor low class'. 


\section{Theory}

The standard two-risky asset model, in either its static (Arrow, 1965) or dynamic (Merton, 1969; Samuelson, 1969) version ${ }^{27}$, predicts that a necessary and sufficient condition for investing in the risky asset $\left(\alpha_{i}^{*}>0\right)$ is that its expected return, $\widetilde{r}$, exceeds the return of the riskless asset, $r$ :

$$
\begin{gathered}
\max _{\alpha_{i} \in\left[0, w_{i}\right]} E^{i}\left\{u_{i}\left[(1+r) w_{i}+(\widetilde{r}-r) \alpha_{i}\right]\right\} \\
\text { FOC }(\mathrm{N} \& S): \quad E^{i}\left\{(\widetilde{r}-r) u_{i}^{\prime}\left[(1+r) w_{i}+(\widetilde{r}-r) \alpha_{i}^{*}\right]\right\}=0
\end{gathered}
$$

$$
\begin{aligned}
\text { Participation Condition: } & E^{i} \widetilde{r}-r>0 \\
\text { Conditional Demand Equation: } & \alpha_{i}^{*} \cong \frac{E^{i} \widetilde{r}-r}{A_{u}^{i}\left(w_{i}\right) \sigma_{i}^{2}}
\end{aligned}
$$

where $E^{i}\{$.$\} denotes the subjective expectation of the decision maker i$ conditional on his individual information set, $I^{i}$. Individuals are thus fully characterized by their preferences, $u_{i}$, initial wealth endowments, $w_{i}$, and beliefs, $E^{i}\{.\} \equiv E\left\{. \mid I^{i}\right\}$, over the available investment opportunities rewarding time, $r$, and risk and time, $\widetilde{r}$. Conditional on the reward for bearing risk being positive $\left(E^{i} \widetilde{r}-r>0\right)$, investors then allocate more or less of their wealth to the risky asset $\left(\alpha_{i}^{*}\right)$ depending on how much do they distaste risk, represented by the absolute risk aversion coefficient, $A_{u}^{i}\left(w_{i}\right) \equiv-\frac{u_{i}^{\prime \prime}\left(w_{i}\right)}{u_{i}^{\prime}\left(w_{i}\right)}$. Risk itself is summarized by the subjective variance of the risky asset return, $\sigma_{i}^{2}$.

In this work we are only interested in the participation condition. For an estimation of the demand for risky assets at both the intensive and extensive margins, see Arrondel et al. (2011).

\section{The conditional subjective expectation}

We extract the information component from subjective expectations, by regressing expectations $\left(\mathrm{PNR}^{i}\right)$ on information $\left(\mathrm{pPNR}^{i}\right)$, and recover the predicted residuals, $\widehat{\epsilon}^{i}$, which are plotted by age in Figure 20 .

For all ages, the regression summary statistics are:

$$
P N R^{i}=\underset{(1.65)}{21.57}+\underset{(0.021)}{0.40} p P N R^{i}+\epsilon^{i} ; \quad R_{N=2,066}^{2}=0.15
$$

When we replace PNR and pPNR in the main equations by the predicted residuals, $\widehat{\epsilon}^{i}$, are only statistically significant for the young, conditional on all other covariates. These results are available upon request.

\footnotetext{
${ }^{27}$ The dynamic (life-cycle) versions that produce a myopic (independent of the investment horizon) optimal share of wealth invested in risky assets, necessitate in addition, that log-returns are normally distributed, independent and identically distributed through time, and investors' preferences in the constant relative risk aversion (CRRA) class. See Brandt (2008) for a detailed explosition.
} 


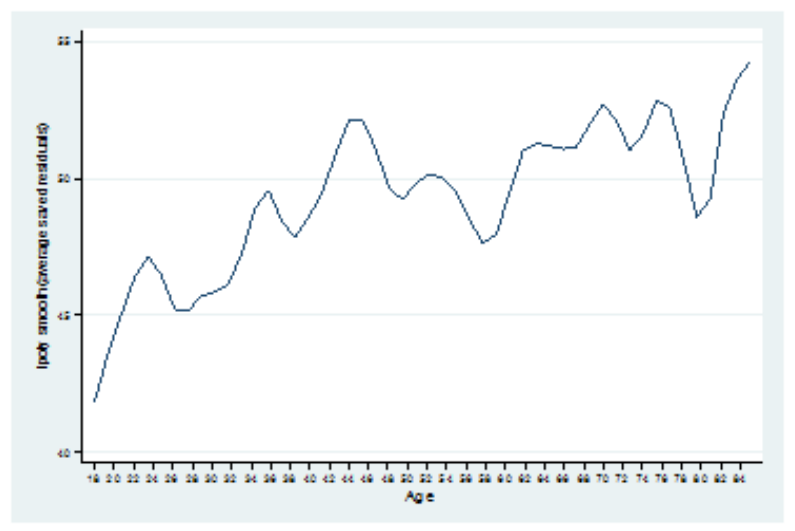

Figure 20: Conditional Subjective Expectation by Age, TNS 2007.

\section{Additional Tables}

\section{Missing/Erroneous answers to the expectations question}

In Table 10, we estimate a Probit specification for erroneous or missing answers ( 1 if answer to qc6 missing or does not add up to 100) as a function of stockholding, and covariates (gender, marital status, education, risk preference)

Table 10: Probability of Missing or Erroneous Answers - Marginal Effects

\begin{tabular}{|c|c|c|c|c|c|}
\hline & $(1)$ & 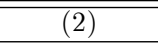 & 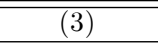 & $(4)$ & 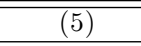 \\
\hline Stockholding & $\begin{array}{c}-0.202^{* * *} \\
(0.0156)\end{array}$ & $\begin{array}{c}-0.198^{* * *} \\
(0.0157)\end{array}$ & $\begin{array}{c}-0.193^{* * *} \\
(0.0158)\end{array}$ & $\begin{array}{c}-0.170^{* * *} \\
(0.0164)\end{array}$ & $\begin{array}{c}-0.158^{* * *} \\
(0.0167)\end{array}$ \\
\hline Male & & $\begin{array}{c}-0.0792^{* * *} \\
(0.0157)\end{array}$ & $\begin{array}{c}-0.0697 * * * \\
(0.0159)\end{array}$ & $\begin{array}{c}-0.0712^{* * *} \\
(0.0161)\end{array}$ & $\begin{array}{c}0.0774^{* * *} \\
(0.0161)\end{array}$ \\
\hline Married/living with a partner & & & $\begin{array}{c}-0.0668^{* * *} \\
(0.0167)\end{array}$ & $\begin{array}{c}-0.0718^{* * *} \\
(0.0169)\end{array}$ & $\begin{array}{c}-0.0614^{* * *} \\
(0.0170)\end{array}$ \\
\hline Education (Ref. category: High school or less) & & & & & \\
\hline Less than college & & & & $\begin{array}{c}-0.168^{* * *} \\
(0.0228)\end{array}$ & $\begin{array}{c}-0.172^{* * *} \\
(0.0229)\end{array}$ \\
\hline College or more & & & & $\begin{array}{c}-0.256^{* * *} \\
(0.0208)\end{array}$ & $\begin{array}{c}-0.258^{* * *} * \\
(0.0208)\end{array}$ \\
\hline Temporal preference & & & & & $\begin{array}{r}-0.0149^{* * *} \\
(0.00296)\end{array}$ \\
\hline Pseudo R-squared & 0.0293 & 0.0343 & 0.0375 & 0.0601 & 0.0651 \\
\hline Chi-squared & 148.1 & 173.2 & 189.4 & 303.3 & 328.8 \\
\hline Log-likelihood & -2449 & -2437 & -2429 & -2372 & -2359 \\
\hline No of observations & 3,826 & 3,826 & 3,826 & 3,826 & 3,826 \\
\hline
\end{tabular}

\section{Descriptive Statistics}


Table 11: Descriptive Statistics

\begin{tabular}{|c|c|c|c|c|}
\hline & \multicolumn{2}{|c|}{ Whole Sample } & \multicolumn{2}{|c|}{ Respondents } \\
\hline & Mean & Std. Dev. & Mean & Std. Dev. \\
\hline Positive Nominal Return (PNR) & 46.45 & 39.68 & 46.45 & 39.68 \\
\hline Past Positive Nominal Return (pPNR) & 68.07 & 37.7 & 68.44 & 37.73 \\
\hline Risk Aversion (CARA) & 39.11 & 3.58 & 39 & 3.77 \\
\hline Age & 48 & 17 & 47 & 16 \\
\hline & \multicolumn{4}{|c|}{$\%$ of the sample } \\
\hline \multicolumn{5}{|l|}{ Account Management } \\
\hline Self account management & & 51.5 & & 52 \\
\hline Financial advisor or other & & 6.1 & & 5.9 \\
\hline \multicolumn{5}{|l|}{ Gender } \\
\hline Male & & 45.6 & & 49.1 \\
\hline Female & & 54.4 & & 50.9 \\
\hline \multicolumn{5}{|l|}{ Marital Status } \\
\hline Married or living with a partner & & 63.2 & & 66.6 \\
\hline Not married or living with a partner & & 36.8 & & 33.4 \\
\hline \multicolumn{5}{|l|}{ Education } \\
\hline High school or less & & 14.8 & & 10.2 \\
\hline Less than college & & 62.2 & & 62.3 \\
\hline College or more & & 23 & & 27.5 \\
\hline \multicolumn{5}{|l|}{ Income Level } \\
\hline Less than $8,000 €$ & & 18.3 & & 15.2 \\
\hline $8,000 €-15,999 €$ & & 32.1 & & 28.8 \\
\hline $16,000 €-29,999 €$ & & 38.4 & & 41.6 \\
\hline $30,000 €$ and over & & 11.2 & & 14.4 \\
\hline \multicolumn{5}{|l|}{ Net Worth } \\
\hline Less than $39,999 €$ & & 21.3 & & 23.3 \\
\hline $40,000 €-149,999 €$ & & 29.1 & & 28.9 \\
\hline $150,000 €-449,999 €$ & & 30.4 & & 24.2 \\
\hline $450,000 €$ and over & & 19.2 & & 23.6 \\
\hline Stockholding & & 30.7 & & 37.5 \\
\hline Firm shares in remuneration & & 4.7 & & 5.6 \\
\hline Liquidity constraint & & 43.6 & & 41.1 \\
\hline Online banking & & 19.7 & & 24.5 \\
\hline No of observation & & 3,826 & & 2,406 \\
\hline
\end{tabular}

Source: TNS 2007. Standard errors are in brackets. 


\section{Further Data Validation}

Table 11 reports table 2 in Dominitz and Manski (2007) and our replication of their table using data from the TNS 2007 survey, for respondents in the same age bracket (50-80 years old):

Among the 50-80 year-olds, the probability of holding stocks is increasing in the percent chance of a positive Stock Market return, albeit in a more volatile way than in the US, since we have less observations:
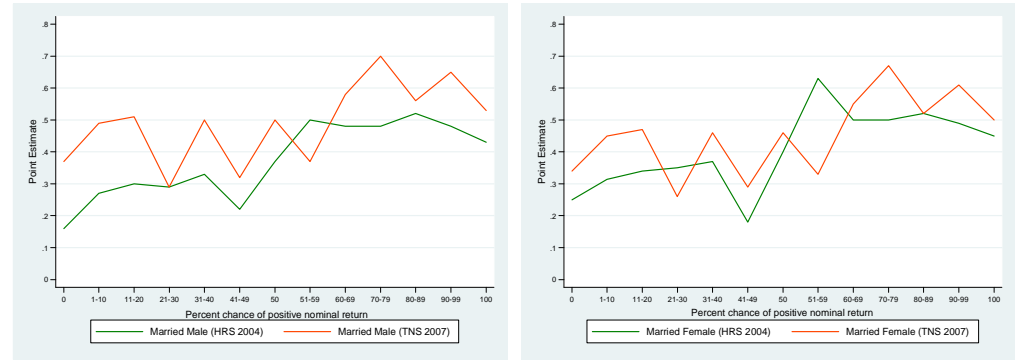

The Probability of Holding Stocks Conditional on the Percent Chance of a Positive Nominal Return (PNR), Gender, and Marital Status. Source (left panel) Dominitz and Manski (2007) and (right panel) TNS 2007.

Table 12 reproduces table 2 in Dominitz and Manski (2007) using data from the TNS 2007 survey, for all ages:

Despite our sample size being substantially smaller and a different elicitation methodology, the positive relationship between expectations and stockholdings conditional on gender and marital status appears strikingly robust. However, since the forecasting horizon is much longer ( 5 years instead of 1$)$, the relationship appears less pronounced quantitatively. In addition, the probability of stockholding is much larger for those who anticipate a $0 \%$ chance of a positive return, and recedes as it increases beyond $80 \%$.

\section{Why don't you invest in the Stockmarket?}

Table 13 reports the frequency of respondents to question qc18, which inquired to non-stockholders, about the reasons for not holding stocks, and the following options were given: (1) I do not have liquidity, (2) It is too risky, (3) I am poorly informed, (4) I do not trust the stock market, (5) Fixed entry costs are too high, (6) Management costs are too high, (7) I have other priorities. 

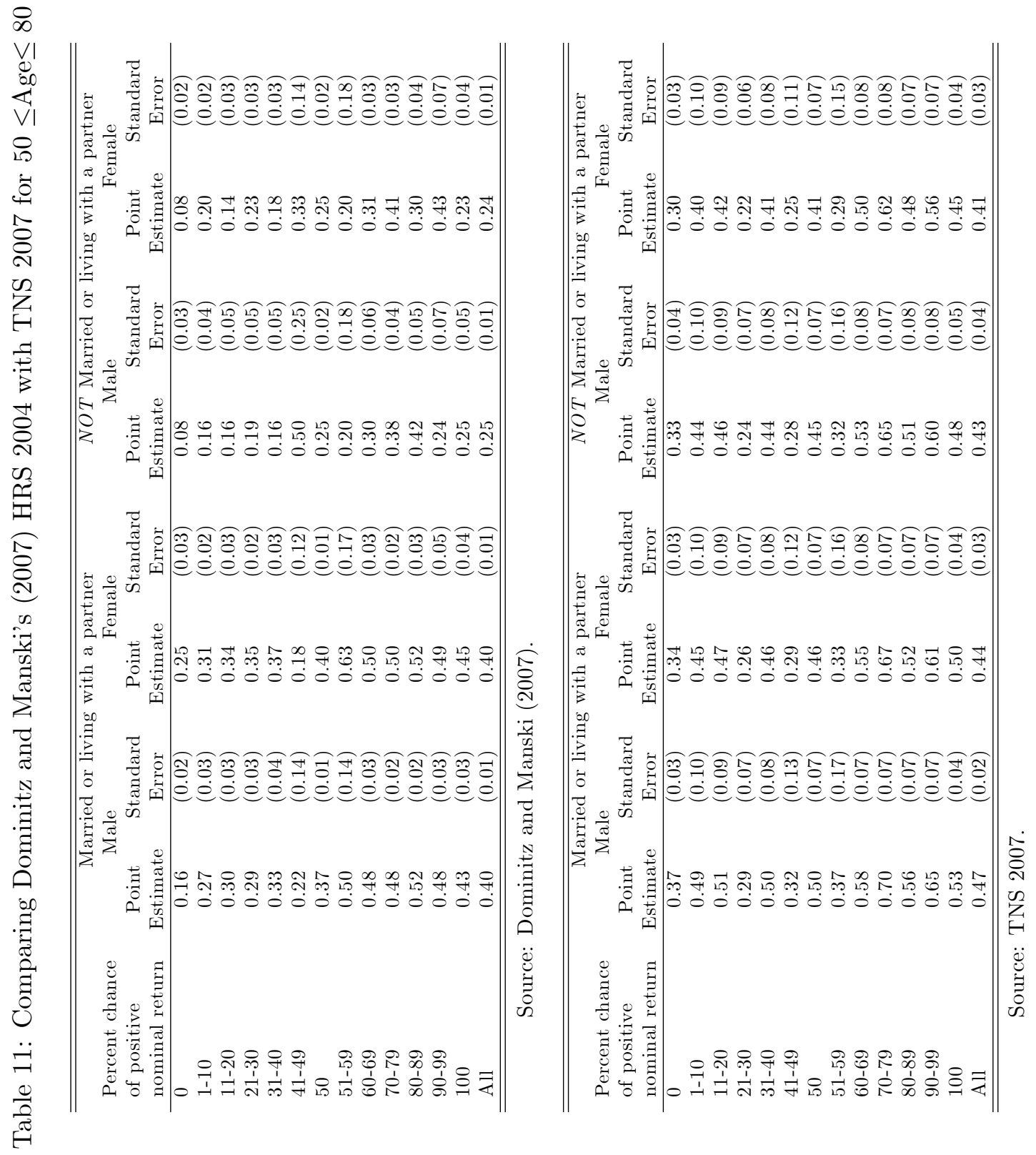
Table 12: Probability of Holding Stocks or Stock Mutual Funds Conditional on Percent Chance of Positive Nominal Return, Gender, Age and Marital Status.

\begin{tabular}{|c|c|c|c|c|c|c|c|c|}
\hline \multirow{4}{*}{$\begin{array}{l}\text { Percent chance } \\
\text { of positive } \\
\text { nominal return }\end{array}$} & \multicolumn{4}{|c|}{ Married or living with a partner } & \multicolumn{4}{|c|}{ NOT Married or living with a partner } \\
\hline & \multicolumn{2}{|c|}{ Male } & \multicolumn{2}{|c|}{ Female } & \multicolumn{2}{|c|}{ Male } & \multicolumn{2}{|c|}{ Female } \\
\hline & Point & Standard & Point & Standard & Point & Standard & Point & Standard \\
\hline & Estimate & Error & Estimate & Error & Estimate & Error & Estimate & Error \\
\hline 0 & 0.31 & $(0.02)$ & 0.28 & $(0.02)$ & 0.25 & $(0.02)$ & 0.22 & $(0.02)$ \\
\hline $1-10$ & 0.39 & $(0.06)$ & 0.35 & $(0.06)$ & 0.33 & $(0.06)$ & 0.29 & $(0.06)$ \\
\hline $11-20$ & 0.40 & $(0.05)$ & 0.36 & $(0.05)$ & 0.34 & $(0.05)$ & 0.30 & $(0.05)$ \\
\hline $21-30$ & 0.28 & $(0.04)$ & 0.25 & $(0.04)$ & 0.23 & $(0.04)$ & 0.20 & $(0.03)$ \\
\hline $31-40$ & 0.48 & $(0.05)$ & 0.44 & $(0.05)$ & 0.42 & $(0.05)$ & 0.37 & $(0.05)$ \\
\hline $41-49$ & 0.41 & $(0.08)$ & 0.37 & $(0.07)$ & 0.35 & $(0.07)$ & 0.30 & $(0.07)$ \\
\hline 50 & 0.42 & $(0.04)$ & 0.38 & $(0.04)$ & 0.35 & $(0.04)$ & 0.31 & $(0.04)$ \\
\hline $51-59$ & 0.24 & $(0.09)$ & 0.20 & $(0.08)$ & 0.19 & $(0.08)$ & 0.16 & $(0.07)$ \\
\hline 60-69 & 0.49 & $(0.05)$ & 0.45 & $(0.05)$ & 0.42 & $(0.05)$ & 0.38 & $(0.05)$ \\
\hline $70-79$ & 0.56 & $(0.04)$ & 0.52 & $(0.05)$ & 0.49 & $(0.05)$ & 0.44 & $(0.05)$ \\
\hline $80-89$ & 0.55 & $(0.05)$ & 0.50 & $(0.05)$ & 0.48 & $(0.05)$ & 0.44 & $(0.05)$ \\
\hline 90-99 & 0.52 & $(0.05)$ & 0.47 & $(0.05)$ & 0.45 & $(0.05)$ & 0.40 & $(0.05)$ \\
\hline 100 & 0.48 & $(0.02)$ & 0.44 & $(0.03)$ & 0.42 & $(0.03)$ & 0.37 & $(0.03)$ \\
\hline All & 0.40 & $(0.02)$ & 0.38 & $(0.02)$ & 0.34 & $(0.02)$ & 0.32 & $(0.02)$ \\
\hline
\end{tabular}

Source: TNS 2007.

Table 13: Reasons for not holding stocks (\%)

\begin{tabular}{lcc}
\hline \hline & Whole sample & Respondents \\
\hline I don't have enough money & 29.8 & 27.6 \\
It is too risky & 19.5 & 19.9 \\
I am uninformed & 11.3 & 11.4 \\
I don't trust stock market & 14.3 & 14.9 \\
Entry costs are too high & 2.63 & 2.99 \\
Management costs are too high & 3.17 & 3.31 \\
I have other priorities & 19.3 & 19.9 \\
\hline \hline
\end{tabular}

Source: TNS 2007. 